\title{
Evaluating the theory of executive dysfunction in autism
}

\author{
Elisabeth L. Hill* \\ Department of Psychology, Goldsmiths College, University of London, Whitehead Building, New Cross \\ London SE14 6NW, UK Fax: +44-020-7919-7873. E-mail address: E.Hill@gold.ac.uk.
}

Received 21 August 2003; revised 23 January 2004

\begin{abstract}
In this paper studies of executive function in autism spectrum disorder are reviewed. Executive function is an umbrella term for functions such as planning, working memory, impulse control, inhibition, and shifting set, as well as for the initiation and monitoring of action. In this review, the focus will be on planning, inhibition, shifting set, generativity, and action monitoring. While it is known that these functions depend upon the frontal lobes, and particularly on prefrontal cortex, very little is known about neuroanatomical correlates of executive function in autism. The review acknowledges the complexity of investigating executive functions in autism, the possible influence of IQ on executive performance in these groups and the possibility of overlap between performance on tests of executive function in other neurodevelopmental disorders that are likely to involve congenital deficits in the frontal lobes, such as attention deficit hyperactivity disorder and Tourette's syndrome.
\end{abstract}

Keywords: Autism spectrum disorder; Executive function; Frontal lobes 
Goldsmiths Research Online

Autism is a developmental disorder characterised by impaired social interaction and communication as well as repetitive behaviours and restricted interests. It is a life-long disorder, with recent population studies suggesting that autism affects at least $0.6 \%$ of the population, and is three times more common in males than females. Learning disability (meaning an IQ under 70) is strongly associated with autism and is present in $25-40 \%$ cases of the disorder (Baird et al., 2000; Chakrabarti \& Fombonne, 2001). In the absence of specific known biological markers, autism is defined using behavioural criteria. The clinical picture of autism varies in severity, and it is now generally agreed that there is a spectrum of autistic disorder. This spectrum includes individuals who are perhaps typified by the 'Rainman' character, through to those who could be considered a rather more 'high-functioning' subgroup, diagnosed with Asperger syndrome. In this review, I will use the term _autism_to refer to individuals across the whole spectrum, and will distinguish the level of ability of participants in the studies reviewed as necessary.

In recent years cognitive theories have been proposed and investigated in an attempt to understand the link between the brain and behaviour in autism. One well-known theory of autism is the theory of mind deficit hypothesis. This hypothesis proposes that a fault in just one of the many components of the social brain can lead to an inability to understand certain basic aspects of communication (see chapters in Baron-Cohen, Tager-Flusberg, \& Cohen, 2000). Although able to account for many of the behaviours typically associated with autism, it is difficult to see how the nonsocial features of autism could be accounted for by the theory of mind deficit hypothesis. The non-social features of autism are rather varied; they include a restricted repertoire of repetitive and obsessive behaviours, rigidity and perseveration as well as an uneven pattern of intelligence. Such non-social features comprise strengths as well as weaknesses and are less well understood and researched than the social impairments seen in autistic disorder. Tests tapping factual knowledge, rote memory and focussed attention on detail can lead to peak performances, while tests tapping_common sense_comprehension and working memory or strategic task planning can be surprisingly poor. These non-social features are currently explained by a number of cognitive theories and their variants. One theory, labelled 'central coherence' can account for some of the patterns of strengths and weaknesses in autism and refers to an information processing style, specifically the tendency to process incoming information in its context-that is pulling information together for higher-level meaning (see Happé, 1999). In the case of strong central coherence this tendency would work at the expense of attention to and memory for details. In the case of weak central coherence this tendency would favour piecemeal processing at the expense of contextual meaning. Recently the extreme male brain theory of autism has been described. This theory explains the autistic profile as showing weaknesses in empathising and strengths in systemising, a drive to analyse or construct systems (Baron-Cohen, 2002).

Over the past decade an influential account of autism has been proposed that is particularly successful at explaining some of the everyday behaviours that are seen in individuals with autism and which are not successfully tackled by the other theories. The major proponents of this explanation of autistic symptoms have been Ozonoff and Russell and their collaborators. In this review I will outline the key approaches to investigating executive dysfunction in autism and I will highlight- where possible-potential links between brain and behaviour.

\section{What is executive function?}

'Executive function' is traditionally used as an umbrella term for functions such as planning, working memory, impulse control, inhibition, and shifting set, as well as the initiation and monitoring of action (Rabbitt, 1997; Roberts, Robbins, \& Weiskrantz, 1998; Stuss \& Knight, 2002). Historically these functions have been linked to frontal structures of the brain, and to prefrontal cortex in particular. These functions share the need to disengage from the immediate environment in order to guide actions. Executive functions are typically impaired in patients with acquired damage to the frontal lobes as well as in a range of developmental disorders that are 
Goldsmiths Research Online

likely to involve congenital deficits in the frontal lobes. Such clinical disorders include attention deficit disorder, autism, obsessive compulsive disorder, Tourette's syndrome, phenylketonuria, and schizophrenia (Ozonoff \& Jensen, 1999; Pennington \& Ozonoff, 1996; Sergeant, Geurts, \& Oosterlaan, 2002).

\section{Executive functions in autism}

The theory of executive dysfunction in autism makes an explicit link to frontal lobe failure in this disorder in analogy with neuropsychological patients who have suffered damage in the frontal lobes and have impaired executive functions. Executive dysfunction can be seen to underlie many of the key characteristics of autism, both in the social and non-social domains. The behaviour problems addressed by this theory are rigidity and perseveration, being explained by a poverty in the initiation of new non-routine actions and the tendency to be stuck in a given task set. At the same time the ability to carry out routine actions can be excellent and is manifested in a strong liking for repetitive behaviour and sometimes elaborate rituals. Repetitive actions dominate in the daily life management of many people with autism. It is well known that they benefit from prompts and externally provided structures which initiate these routines or help them switch set.

In this section, I will discuss studies of executive function in autism that have included wellmatched control groups. These studies will be grouped by separate executive functions labelled in the traditional manner; specifically planning, mental flexibility, inhibition, and self-monitoring. The emerging picture is rather unclear. One reason for this may be that many studies involve children and adolescents with a wide age range, and/or with IQs below the normal range (or at least ranging from below to the normal range). In contrast, the handful of studies that have reported on adult samples (individuals aged 17 years and older) have included participants with an IQ within the normal range. In this review, studies are considered in relation to the general ability of participant groups rather than age, although both tend to be confounded. Grouping by ability means that appropriate control groups di.er according to the ability level of the autistic group studied. For individuals with autism but without a learning disability, a chronological and IQ matched normally developing group would be appropriate. Other appropriate control groups, would be dyslexic individuals who experience a specific disability but in whom a general learning disability is not part of the diagnostic criteria. This disorder has not been associated with executive dysfunction. For individuals with autism plus a learning disability, a peer group matched for chronological age and IQ ability would be needed. This, in turn, raises its own concerns. Groups of children with moderate learning difficulties (MLD) typically include individuals with no known cause for their learning disability (often excluding individuals with Down syndrome, for example), but what constitutes a learning disability and whether learning disabilities are independent of specific causes is unclear. A recent study conducted in California has suggested that along with an apparent increase in the diagnosis of autism comes a similar decrease in the diagnosis of learning disability (Croen, Grether, Hoogstrate, \& Selvin, 2002), questioning whether many of the children included in MLD control groups in past autism studies were in fact true cases of MLD. Some may have been cases of autism plus MLD. In this case, ambiguous results would be expected across studies since some groups of MLD controls might include a greater number of undiagnosed autistic individuals than others. Thus, an autistic and MLD group would be expected to perform more similarly to one another in studies where the MLD group unwittingly included more autistic cases than when it did not. These

methodological issues have yet to be resolved but are critical when setting up research studies and evaluating the outcome of studies of executive function in autism.

\section{Planning in autism}

Planning deficits have been found in children and adolescents with autism (see Table 1). Planning is a complex, dynamic operation in which a sequence of planned actions must be constantly monitored, re-evaluated, and updated. This requires the conceptualisation of changes from the 
current situation, looking ahead by taking an objective and abstracted approach to identify alternatives, making choices, and then implementing the plan and revising it accordingly.

One typical task used to assess planning is the Tower of Hanoi, or the related Tower of London, in which individuals must move disks from a prearranged sequence on three different pegs to match a goal state determined by the examiner. This must be done in as few moves as possible and following a number of specific rules. Children and adolescents with autism have been found to be impaired on such tasks. This is the case in relation to an age-matched clinical control group of participants with various developmental disorders including dyslexia, ADHD and Tourette syndrome (Bennetto et al., 1996; Ozonoff \& Jensen, 1999; Ozonoff et al., 1991) as well as in comparison to an age-matched normally developing group (Ozonoff \& Jensen, 1999).

Furthermore, in the sample of individuals with autism versus mixed developmental disorders reported by Ozonoff et al. (1991), this impairment was maintained over time (Ozonoff \& McEvoy, 1994). In all these studies, the group mean IQ level fell just within the lower end of the normal range. The one study that has assessed planning in a small group of adult men with autism included only those whose IQ fell within the normal range. In this study, planning was evaluated using the Trail- Making B test (Army Individual Test Battery, 1944), in which dots marked with letters and numbers must be joined together in ascending order, alternating between numbers and letters (joining 1 to A to 2 to B, etc). The autistic group showed a deficit in planning on this test in comparison to a group of normal control men matched for age, IQ, and education level (Rumsey \& Hamburger, 1988).

From these studies it appears that children, adolescents, and adults with autism experience an autism-specific deficit in planning in relation to normally developing individuals and those with other disorders not associated with generalised learning disability. While the mean IQ level for each group reported fell within the normal range, the range of IQ levels included in the studies (generally a FSIQ greater than 69 although greater than 80 in the adult study described) makes it unclear as to whether the identified planning deficit reflects an effect of autism in all individuals or of learning disability in some. Some light may be shed on this question if we consider a detailed study employing a form of Tower task in an autism group in comparison to two control groups, one matched for age and learning disability, and the other for ability level.

Hughes et al. (1994) used a variant of the Tower of Hanoi/London task, the 'Stockings of Cambridge,' in which puzzles are presented in a computerised format. This allowed comparison of performance on several different components of Tower tasks. Each puzzle presented had a yoked control item that provided baseline reaction time and motor execution times for each puzzle. In this way, initial planning times and thinking times could be estimated. In this study, the performance of children and adolescents with autism was compared to that of two control groups. One control group was matched to the autistic individuals for age and (moderate)

learning disability and the other was a younger normally developing control group selected to match the approximate verbal and non-verbal mental ages of the autistic participants. On this test the autistic group was impaired relative to both comparison groups. However, this autism-specific planning deficit was not universal across all instances of the planning task. The authors divided the puzzles according to the number of moves required to move from start- to end-state, categorising the puzzles as one of two types. 'Easy' puzzles required two or three moves to reach the end-state, whereas 'difficult' puzzles required four or five moves to do so. The autistic deficit was seen only on those puzzles conceptualised as 'difficult,' and not on 'easy' puzzles. This suggests that autistic individuals do not struggle with planning across the board, rather that difficulties with planning exist at more complex levels. In day-to- day life it is likely that planning occurs almost entirely at this complex level. This might explain why planning appears to be particularly problematic to autistic individuals in their daily lives.

In the Hughes et al. (1994) study, a non-executive explanation of an autism deficit could be ruled out. The inclusion of the yoked control puzzles identified that the difference between the autistic and comparison groups was not due to motoric impulsivity in the autistic group but rather to a 
planning impairment. In addition, each participant group was divided into two on the basis of non-verbal mental age. For the easy problems, those participants in each participant group with higher nonverbal mental ages showed faster initiation times. For all puzzles, these same participants showed shorter mean motor execution times per move, in comparison to those individuals in each group with low non-verbal mental ages. This finding suggests that general ability per se has at least some influence on successful planning abilities, and that autism is not by any means the only cause of the observed deficit. Autism may be a contributing factor, indeed autism plus learning disability may lead to an additive deficit.

Overall, then, children, adolescents, and adults with autism exhibit a planning impairment, as assessed by Tower tasks. Furthermore, studies that have used alternative tests considered to assess planning have highlighted impairments in children with autism. Slowed performance on the Milner mazes (Milner, 1965) was reported by Prior and Hoffmann (1990) in comparison to two control groups matched for either chronological or mental age. In addition Hughes (1996) found that autistic children were impaired in their planning of underhand reaches on Luria's bar task. In this simple 'reach, grasp, and place' task the use of particular hand positions leads to either comfortable or awkward final hand positions depending upon an individual's planning ability. These results suggest an autistic planning deficit for a simple goal-directed motor act, again in relation to an age and learning disability matched comparison group as well as a younger normally developing comparison group.

However, negative results have also been found. Mari, Castiello, Marks, Marraffa, and Prior (2003) have reported a planning deficit in a kinematic reach-to-grasp task in low-IQ (70-79 IQ points) autistic children in comparison to both average-IQ autistic (80-109 IQ points) and chronologically age matched normally developing children, suggesting that planning in their task was related to IQ rather than to autism. Furthermore, performance on the Mazes subtest from the Wechsler Intelligence Scale for Children (WISC-R, Wechsler, 1974) did not distinguish between the performance of a group of children with high-functioning autism in comparison to a group of children with a developmental language disorder (DLD; Liss et al., 2001). These two groups were matched for chronological age, socioeconomic status, full scale IQ and non-verbal IQ. The DLD group had a significantly higher mean verbal IQ than the autistic group. Unfortunately no non-disordered control group was included. Recently Bishop and Norbury (2002) reported that children with autism cannot be as clearly discriminated, on the basis of parental report, teacher report, and behavioural observation, from children with language impairments as diagnostic criteria dictate. Thus, the finding reported by Liss et al. may reflect diagnostic overlap or similar cognitive processing impairments between these two groups that would indicate that a language disordered group is not the right comparison group if we are to understand executive functioning in autism.

Thus, while the picture of executive dysfunction in autism with regard to planning may seem clear, careful consideration of the issues suggests that the waters are muddy. It may be more informative to focus on the influence of learning disability on planning performance, as well as any additive effect of autism plus learning disability before being able to come to reliable conclusions as to the nature of any planning deficit in autism and the implications of this for a specified theory of executive dysfunction. A further difficulty is the choice of tasks that can be used to assess executive functioning reliably. Tasks such as the Tower tasks are complex and involve a number of processes over and above planning per se (e.g., working memory, inhibition of prepotent but inefficient subgoal moves). These need to be well controlled in future studies. Moreover, within the normal population such planning tests have been shown to have low test-retest reliability (Bishop, Aamodt-Leeper, Creswell, McGurk, \& Skuse, 2001; Lowe \& Rabbitt, 1998). As Bishop et al. have reported, this suggests that we should be cautious when using these tests to index the integrity or maturation of underlying neurological systems in children. 
Goldsmiths Research Online

\section{Mental flexibility in autism}

Mental flexibility is another executive function, and is often termed 'set-shifting' or cognitive flexibility. These terms refer to the ability to shift to a different thought or action according to changes in a situation. Poor mental flexibility (used here interchangeably with the term setshifting) is illustrated by perseverative, stereotyped behaviour, and di.culties in the regulation and modulation of motor acts.

Perseveration is a widely acknowledged consequence of poor executive functioning that is seen in autistic individuals. Perseveration in autism has been attributed to a deficit in mental flexibility. One example of this is seen when performing the Wisconsin Card Sorting Task (WCST; Heaton, Chelune, Talley, Kay, \& Curtiss, 1993; Nelson, 1976). In this task an individual must sort cards on one of three possible dimensions (colour, number, and shape) according to a non-spoken rule and then shift to sort cards along a different dimension. On this task, the experimenter tells the participant whether s/he has placed the card correctly (i.e., followed the correct rule), but does not give the participant the rule explicitly. On this task, a perseverative error is viewed as a failure to shift set to the new sorting criterion. A number of studies have employed the WCST and although comparison is hindered by the use of different measures for scoring (e.g., total number of errors, number of perseverative errors, and categories completed), studies have tended to focus on the number of perseverative responses shown by participants. Autistic children and adolescents are highly perseverative in their response to this task. That is, autistic individuals have difficulty in shifting to sort using the second of two rules, rather they continue to sort using the .rst rule. This is true in comparison to both normally developing comparison groups (Ozonoff \& Jensen, 1999; Prior \& Hoffmann, 1990) and clinical groups including children with language impairments, dyslexia, and ADHD (Bennetto et al., 1996; Liss et al., 2001; Ozonoff \& Jensen, 1999; Ozonoff et al., 1991) and those with psychiatric conditions (Szatmari, Tuff, Allen, Finlayson, \& Bartolucci, 1990; but see Nyden, Gillberg, Hjelmquist, \& Heiman, 1999). Ozonoff and McEvoy (1994) followed up the participants reported by Ozonoff et al. (1991) and found a continuing impairment in the number of perseverations made on the WCST by autistic children and adolescents, in comparison to a well-matched clinical control group of children and adolescents with developmental disorders such as dyslexia and ADHD. The finding of a significant deficit on the WCST is not restricted to Western cultures, having been reported in a group of Taiwanese autistic children in comparison to an age-matched normally developing control group (Shu, Lung, Tien, \& Chen, 2001). Thus, studies of individuals with autism which include at least some individuals that would be considered to show a learning disability suggest increased rates of perseveration in individuals with autism on the WCST. While the perseverative responses on the WCST of these individuals have not been related to their perseverative tendencies in daily life, the findings would be suggestive of this. A summary of studies investigating mental flexibility in autism is given in Table 2.

What of the performance of autistic individuals in which the whole autistic group is made up of individuals whose IQs fall within the normal range? Such studies appear to have been conducted only in adults. Indeed, Rumsey (1985) was perhaps the first to report performance on this test with an autistic group, reporting that the autistic adults were impaired relative to a control sample matched for age, IQ, gender, and education level on a wide range of measures, including number of categories correct and perseverative errors. In two later studies, the number of categories completed was reported for autistic men in relation to comparison groups matched for age, IQ, gender, handedness, and education level. Autistic adults were impaired on the WCST in comparison to both normal controls (Rumsey \& Hamburger, 1988, 1990) and to a dyslexic control group (Rumsey \& Hamburger, 1990). However, it should perhaps be noted that while all autistic individuals in these three studies had a FSIQ of 80 or above, the range of FSIQ in the control groups was higher, reported to range between 90 and 119. Steel et al. (1984) have also reported the case of an autistic adult (D.S.) with an IQ in the low normal range (measured as 81-91) who showed perseverative responses on the WCST in comparison to standardised data. 
Goldsmiths Research Online

Do autistic individuals perform poorly on the WCST across the board? Perhaps not. Minshew et al. (1992) reported no difference between the number of perseverative errors produced by a group of adults and adolescents with autism (FSIQ greater than 70 in each participant) and a wellmatched age, IQ, gender, and ethnic origin normal control group on the WCST. This is in contrast to the results reported in the Rumsey and Hamburger studies which had employed an autistic group with a slightly higher level of IQ. It seems likely, however, that this difference arises from the nature of the measures used across the two studies. However, it should be noted that some significant differences on WCST measures disappear when the effects of verbal IQ or fullscale IQ are removed from the analysis. While this statistical manipulation has not been considered in many studies, it has been shown to remove significant group differences on percent perseverative errors (Rumsey, 1985), number of perseverative errors (Liss et al., 2001; Rumsey, 1985) and number of non-perseverative errors (Rumsey, 1985). Therefore, perseverative ability may be highly related to verbal IQ. In this light, it would seem appropriate to co-vary verbal IQ in future studies irrespective of whether comparison groups have been matched for verbal ability.

Do any measures of the WCST appear to be impaired consistently in autistic samples, irrespective of the test measures or comparison groups adopted? A summary of studies employing the WCST indicates that autistic deficits are seen most consistently in terms of the number of categories correct and total number of errors made. The picture may be clouded because of the general emphasis on perseverative errors alone when using the WCST. Patients with acquired damage to the prefrontal cortex have been shown to make as many random as perseverative errors on the WCST (Stuss \& Knight, 2002), and this may also be a truer reflection of the autistic

profile. Detailed study of performance on the WCST by patients with focal frontal lobe lesions has revealed varying performance profiles according to the site of the lesion (Stuss et al., 2000), which may contribute to a clearer understanding of the varied autism profile on this task. While the summary presented here seems to eliminate increased perseveration as accounting for the impaired performance of autistic groups, this is not to suggest that perseveration is not seen widely on the WCST, or that perseverative behaviour is not a difficulty seen in autistic individuals. On the contrary, perseverative behaviour is seen widely in the daily life of autistic individuals. Indeed, increased perseverative errors have also been shown in a language task (Waterhouse \& Fein, 1982). Detailed research is needed to establish whether perseverative behaviour occurs across the autism spectrum or is constrained to those falling below a certain ability level, and whether perseverative behaviour is related directly to stereotyped and rigid behaviour in everyday life, as shown in highly repetitive thought and action.

One study has documented the performance of autistic children and adolescents on a test of setshifting that is not the WCST. Hughes et al. (1994) report performance on the Intradimensionalextradimensional shift (ID/ED shift) task of the Cambridge Neuropsychological Test Automated Battery (CANTAB). This ID/ED shift task is simpler than the WCST, allowing participation by a wider range of individuals. The task is presented in several stages, providing a more precise identification of the locus of difficulty on a set-shifting task than is possible using the WCST. In the test, discrimination must be made between one of two (or in later stages, four) stimuli, with shifts in discrimination required within- (ID) and between- (ED) set (pink shapes and white lines, respectively). Hughes et al. tested children and adolescents with autism in comparison to two control groups. One control group was matched to the autistic individuals for age and (moderate) learning disability and the other was a younger normally developing control group selected to match the approximate verbal and non-verbal mental ages of the autistic participants. The autistic group was impaired in comparison to both of the comparison groups only in the final stages of the task, that is when an extradimensional shift was required. This study suggests that it is not that autistic individuals perseverate in a global sense, rather that they experience an autism-specific 'stuck-in-set' perseveration.

The performance of adults with autism has not been assessed using tests of setshifting other than the WCST. In the future it will be critical to investigate autistic adults whose general ability falls 
Goldsmiths Research Online

within the normal range on tasks such as the ID/ED shift in order to establish how widespread a stuck-in-set perseveration may be within the autistic spectrum.

Much like the picture that emerged about planning in autism, while the initial view has been that autistic individuals show significant numbers of perseverations on tests of mental flexibility in comparison to a variety of control groups, detailed consideration of a number of studies and issues suggests that the picture is more complex. Since inhibition (discussed separately below) is a clear feature of tasks such as the WCST this and mental flexibility should not be within the same participants. Furthermore, task presentation may be critical to performance level in autistic individuals. For example, when comparing the standard and computerised versions of the WCST in a sample of children and adolescents matched for age and full-scale IQ to a group of nondisabled controls (for inclusion in the study all participants had to have a full-scale IQ of 70 and above) Ozonoff (1995) reported that performance of the autism group was particularly attenuated in the computer condition. In the future it will be important to focus on the influence of a number of factors in order to come to reliable conclusions as to the nature of any mental flexibility deficit in autism and the implications of this for a specified theory of executive dysfunction. At present important issues would appear to include the influence of verbal ability on mental flexibility as well as the impact of learning disability, and any additive effect of autism plus learning disability.

\section{Inhibition in autism}

Inhibition is a further aspect of thought and behaviour attributed to executive function that has been investigated in autistic samples (see Table 3). The Stroop task (Stroop, 1935) is a classic example of a test of inhibition. In this task the interference of one input can be measured on the performance of another (e.g., naming the ink colour of colour words when the word and ink are either congruent-the word 'red' printed in red ink-or incongruent-the word 'red' printed in green ink). Many Stroop-like tasks have been reported which draw on the fundamental principle of the colour Stroop task, with varying degrees of success. Overall, the evidence indicates that autistic children and adolescents show equal amounts of interference on this task in comparison to normal control groups (Eskes et al., 1990; Ozonoff \& Jensen, 1999). This is in contrast to other developmental disorders associated with executive dysfunction such as ADHD (Ozonoff \& Jensen, 1999) and PKU (Diamond, Prevor, Callender, \& Druin, 1997).

The inhibitory ability of autistic individuals has been investigated further. Using a Go/No-Go task as well as Stop-Signal and negative priming tasks, Sally Ozonoff and her colleagues compared a group of children and adolescents with autism (with fullscale IQs within the normal range) to a group of normally developing individuals well-matched to the autistic participants for age, IQ, and gender. The findings of two studies assessing vulnerability to perseveration suggest intact inhibitory skill in autism. On a Go/No-Go task autistic and normal individuals did not differ in a neutral inhibition condition, where on half of 200 presented trials a response must be made and on the other half of trials no response must be made. In this instance, no inhibition of cognitive set is required (Ozonoff et al., 1994). On a Stop-Signal test, the autistic participants again did not differ from the normally developing individuals in their ability to inhibit a motor response to both neutral and prepotent stimuli (Ozonoff \& Strayer, 1997). On a negative priming task, autistic individuals showed the normal level of interference when the target letters in a stimulus had been the distractor items on a previous trial. (In this study, participants were shown a string of five letters, e.g., 'FTFTF,' and asked to judge whether letters two and four were the same or different. Respondents were typically slower and less accurate to make a response when a letter in position two or four was shown in positions one, three, and five on the previous trial. This is a standard negative priming effect. A more widely used test of negative priming requires participants to respond whenever a circle appears. During the first phase of a trial-the prime phase-a participant might see a circle and a triangle and must touch the triangle and ignore the circle. During the second phase of a trial-the probe phase-if the triangle appears where the circle had been a participant's reaction time to touch the triangle is typically slower.) Thus, autistic 
Goldsmiths Research Online

individuals were equally able to inhibit the processing of irrelevant stimuli in a visual display as were their well-matched peers (Ozonoff \& Strayer, 1997). Overall, these two studies have highlighted that at least two components of inhibition are spared in non-retarded individuals with autism.

There is one kind of inhibition that studies have consistently found to be impaired in autism: the inhibition of a prepotent response. One illustration of this is given by Russell et al.'s (1991) and Hughes and Russell's (1993) studies using the Windows Task. In this task a participant can win a desired object (chocolate) by pointing to one of two boxes, one of which can be seen to contain the chocolate. However, in order to win the chocolate the participant must point to the empty box, that is the one without the chocolate. Children with autism had significant difficulty inhibiting their prepotent desire to point to the chocolate, the move that meant that the experimenter, rather than the child retained the chocolate. Their perseverative behaviour on this task (not responding to the negative feedback of not winning the chocolate) was seen in comparison to a mental age matched control group, and has recently been shown across 20 trials of an automated version of the Windows Task (Russell, Hala, \& Hill, 2003). Hughes and Russell (1993) developed a second task involving the inhibition of a prepotent response, without the social component of the competitor who was present in the Windows Task. In this 'detour reaching task' participants could obtain a marble visible in a box, but only by turning a knob or flicking a switch at the side of the box, and not by reaching immediately into the box. Individuals with autism found it much more difficult to throw a switch in order to perform an object retrieval than children with moderate learning difficulties with whom they were matched for verbal mental age (verbal mental age, mean autism 6.58 years SD 2.6; mean MLD 6.17 years SD 1.38). Children with autism were less able to inhibit their prepotent response to reach immediately for the marble on this task. Further work manipulating this paradigm reported by Bíro and Russell (2001) suggests that it may be the apparently arbitrary nature of the rules involved that cause particular difficulty in this area of executive functioning for learning disabled children with autism. Furthermore, Russell postulates that the difficulty with Tower (planning) tasks and with the WCST (set-shifting) is that the rules appear to lack a rationale and that it is this arbitrary nature of the rules imposed that leads to the observed autism deficit. Tasks that have an executive component but in which rules do not lack a rationale-such as A-not-B tasks (Piaget, 1954) and the Tubes task (Hood, 1995) - are passed by children with autism (Russell et al., 1999a, see also Russell, 1997, 2002). Such tasks need to be repeated in a sample of normative-IQ individuals with autism in order to establish whether the apparently normal ability to inhibit identified in the studies of Ozonoff and colleagues described above applies also to the inhibition of a prepotent response, or whether the inhibition of a prepotent response is an area of difficulty for autistic individuals of all ability levels. It may be that certain inhibition difficulties are present only in learning disabled autistic individuals. The influence of general ability level on executive functioning in autism will be discussed below.

\section{Generativity in autism}

Turner (1997) has postulated difficulties in the capacity to generate novel ideas and behaviours spontaneously as an underlying cause of the lack of spontaneity and initiative seen in autism, the poverty of speech and action and the apparent failure to engage in pretence. Furthermore, such an impairment may also be related to the high rates of repetitive behaviour characteristic of autism as well as avoidance and dislike of change (Turner, 1997).

The regulation and generation of novel ideas, which are assumed to involve executive functions, have been investigated in autism in a small number of studies (see Table 4). In a drawing study, Lewis and Boucher (1991) provide some evidence that successive drawings of children with autism show a greater degree of thematic relatedness than equivalent drawings made by nonautistic control children. Furthermore, on tests of word fluency where an individual must produce as many words as possible in one minute, individuals with autism have been shown to be 
impaired in relation to non-autistic, age, and ability matched controls (Minshew et al., 1992; Rumsey \& Hamburger, 1988), although others have failed to find such differences (Boucher, 1988; Minshew et al., 1995; Scott \& Baron-Cohen, 1996). However, the Boucher (1988) study reveals a difficulty in characterising a word fluency task as a good test of the generation of novel responses. In this study, children with autism were unimpaired in relation to both learning-disabled and age-matched control groups when generating words belonging to a specific category (e.g., colours, animals). However, the same children with autism showed impoverished responses in comparison to both control groups when asked to produce as many miscellaneous (unrelated) words as possible in one minute. In this condition, participants were given no cues to aid retrieval of generation strategies. Finally, Jarrold et al. (1996) investigated generativity in children with autism through pretend play, finding that while such children could engage in the mechanics of pretend play, they showed an impairment in the spontaneous production of pretence. The authors argued that this impairment arose from a difficulty in generativity.

In a comprehensive study of generativity, Turner (1999) investigated individuals with autism aged 6-32 years who were grouped according to verbal IQ (76 or above vs. 74 or below) and who were compared to age, verbal IQ, and non-verbal IQ as well as verbal mental age matched control groups. Tests of verbal fluency (e.g., produce as many words as possible beginning with the letter F within $60 \mathrm{~s}$ ), ideational fluency (e.g., produce as many uses for a newspaper as possible within two and a half minutes) and design fluency (e.g., produce as many different designs as possible within $5 \mathrm{~min}$ ) were administered. Responses on the verbal and ideational fluency tests suggested that autistic individuals are impaired in the generation of novel responses and behaviour, while the findings of the design fluency tests were equally consistent with an impairment in the regulation of behaviour through inhibition and/or monitoring. In this study, the presence/absence of an autistic diagnosis, rather than IQ, discriminated performance, with those high-functioning individuals with autism showing particularly impoverished performance in some aspects of the analyses. Importantly, Turner (1997) reported a correlational link in autistic individuals between poor performance on ideational and design fluency tasks and high levels of repetitive behaviour in daily life.

What would be the consequences of a generativity impairment in autism? Turner (1999) discusses this in the following terms: In addition to disrupting spontaneous behaviour, an impaired capacity to generate novel behaviour would hinder the execution of routine behaviour where changed circumstances occur, or some form of trouble-shooting is required. This is problematic because of the need to generate new hypotheses for the restructuring of routine behaviours. This happens frequently, for example, adapting the routine for coffee making when the sugar runs out or the milk is spilt. Turner argues that this highlights the importance of studying generativity in autism as a potential explanation for the ability to control, regulate, and modify behaviour in all areas of functioning, and not just those clearly implicated by executive dysfunction accounts of autism. Certainly the impact of a generativity deficit in autism and its relationship to all aspects of the disorder warrants further, detailed investigation.

\section{Self-monitoring in autism}

A further component of executive functions considered in relation to autism is self-monitoring. By this is meant the ability to monitor one's own thoughts and actions, as well as to self-correct those thoughts and actions (see Table 5).

A deficit in self-monitoring might be seen in perseverative behaviour, since this may be the mental operation required for an individual to disengage from the immediate context in order to guide behaviour by reference to mental models, changes in the environment or future goals. Selfmonitoring has been the subject of a number of studies of Russell's Cambridge group, who take self-monitoring to refer to the subpersonal processes that enable individuals to take themselves to 
Goldsmiths Research Online

be the source of self-determined changes in perceptual input, actions, and mental episodes. There is evidence suggestive of a self-monitoring deficit in autism as seen through autistic deficits in tests of motor estimation (Frith \& Hermelin, 1969; Hermelin \& O'Connor, 1975), error correction and avoidance (Russell \& Jarrold, 1998), motor error correction (Hughes, 1996), impairments of intention monitoring (Phillips et al., 1998), and memory for actions (Russell \& Jarrold, 1999). These impairments have all been conceptualised post hoc as evidence for impairment of executive function, and specifically of self-monitoring (see Russell, 1997, 2002). However, studies that have been devised to assess self-monitoring directly have provided little evidence of a specific deficit in self-monitoring in individuals with autism with respect to matched control groups of both children with moderate learning disability and normally developing children (Hill \& Russell, 2002; Russell \& Hill, 2001). Thus, the evidence concerning an impairment in self-monitoring in autistic individuals is mixed and further detailed, theory-driven studies are needed. In addition, the specific tasks used have generally been new, experimental tasks in the sense that they have not been widely tested and are not, therefore, wellknown tests of executive function.

\section{Executive function in autism across the lifespan}

The majority of studies cited above recruited children and adolescents with autism as participants. These studies have highlighted areas of executive dysfunction in autistic individuals in the context of preserved ability in other neuropsychological domains and in individuals of varied IQ levels. However, in order to evaluate the possible role of executive dysfunction in the autistic disorder (as either a primary or secondary deficit), it is necessary to have a picture of executive functioning across the typical lifespan.

The neural circuitry that forms the core of prefrontal cortex begins to develop by the second trimester of pregnancy (Goldman-Rakic, 1987). Post-natally the frontal lobes are the brain areas that take the longest to mature. Indeed, they are considered to develop over the first 20 years of life (e.g. Giedd et al., 1996, 1999; Huttenlocher, 1979, 1990; Sowell et al., 1999a, Sowell, Thompson, Holmes, Jernigan, \& Toga, 1999b, 2001). In the past, research tended to underestimate the executive function abilities of children and it was generally thought that frontal lobe development started later in childhood. More recent physiological and psychological evidence suggests that rapid changes occur in the development of the frontal lobes far earlier than was previously thought, between 6 and 12 months (e.g. Chugani, 1994; Goldman- Rakic, 1987) with a corresponding increase in behavioural abilities at this time including language, mobility, and coordination. Furthermore, executive functions may emerge in a multi-stage process that is consistent with the growth spurts identified within anterior brain regions (see Anderson, Levin, \& Jacobs, 2002). Subcomponents of executive functions may possess different developmental trajectories and mature at different rates (Anderson et al., 2002; Diamond, 2002; Fischer, Biscaldi, \& Gezeck, 1997; Zelazo, Reznick, \& Pinon, 1995, 1996, 1997). The behaviour measured would thus reflect mediation by different areas of the frontal lobes as they mature differentially. It is plausible that greater understanding of this maturation process, combined with cautious integration of information gleaned from the behaviour of patients with acquired frontal lobe lesions, could help increase understanding of the pattern of intact and impaired executive function performance in autism.

A number of studies have considered the development of executive functions in normally developing children. For example, Levin, Culhane, Hartmann, Evankovich, and Mattson (1991) report data from normally developing 7-8, 9-12, and 13-15 year olds on a series of tests believed to be associated with frontal lobe function including the WCST, Californian Verbal Learning test (CVLT), word fluency, animal naming, design fluency, twenty questions, Go/No-Go, the Tower of London and a delayed alternation task. Significant performance differences existed between the age groups on all tasks except one (delayed alternation). However, particularly striking gains were 
Goldsmiths Research Online

seen at different ages on different tasks. For example, impressive gains in concept formation, the capacity to shift set and to suppress inappropriate responses were seen before adolescence on the WCST, as well as a major decrease in the number of false positives produced on the Go/No-Go task. In contrast, significant improvements in performance on the Tower of London task were not observed until adolescence when improvements in planning and execution of sequences were observed. Additionally, adolescents showed a significant increase in their ability to utilise semantic information in the 20 questions task and to cluster responses on the CVLT. A principal component analysis revealed three factors: a semantic association/ concept formation factor, a freedom from perseveration factor, and a planning/ strategy factor. Longitudinal study across a wider age range than that included by Levin et al. would identify more specifically the nature of these factors as well as indicating whether they mature at different times.

More recent studies have started to fractionate research of executive functions in young children. For example, Diamond and her colleagues have focused on studying improvements in cognitive functions that depend on the prefrontal cortex (PFC), and particularly the dorsolateral prefrontal cortex (DLPFC), across childhood. By adopting tasks used with monkeys it is possible to test young children who are not able to be assessed using standard neuropsychological tests of frontal lobe function. Findings that young children improve on the delayed response (similar to Piaget's A-not-B task) and object retrieval (Diamond, 1988, 1990, 1991) tasks over the first year of life, in combination with anatomical and biochemical evidence of PFC maturation during this time suggest that early changes are seen. These changes continue throughout childhood and into adulthood (see Diamond, 2002). They are shown across a range of tasks such as inhibition of a prepotent response (Kochanska, Murray, \& Harlan, 2000), the day-night task (Gerstadt, Hong, \& Diamond, 1994), Luria's tapping test (e.g. Diamond \& Taylor, 1996), and the directional Stroop task (Davidson, Cruess, Diamond, O_Craven, \& Savoy, 1999).

As noted previously, only a handful of studies have recruited autistic adult participants, and these have reported deficits in the two executive domains assessed, planning, and mental flexibility. What though of the performance of preschool-aged children with autism on tests of executive function? A small handful of fairly recent studies have investigated executive functions in this population. Given the extended development of the frontal lobes and therefore executive functions, and the complexity of tasks of executive function used with older children and adults, it is unfortunately not possible to use the tasks described in early sections of this paper with young children. Other tasks must be drawn on and parallels made.

Geraldine Dawson and her colleagues have investigated the neuropsychological correlates of the early symptoms of autism in children younger than those included in the studies described above. Across two studies, tasks considered to tap frontal lobe function that are appropriate for very young children (tasks requiring no linguistic response) were employed. In comparison to developmentally matched (for receptive language) normally developing children and children with Down syndrome, autistic children (mean age, 64.6 months) were impaired on a delayed response task (similar to the A-not-B task in infants) when non-verbal mental age had been covaried. This task is one on which performance is impaired in non-human primates following lesions to the dorsolateral prefrontal cortex. The same pattern of performance was observed on a delayed non-matching to sample task (DNMS), again with non-verbal mental age covaried. This task is believed to implicate the ventromedial frontal cortex, and particularly the orbital prefrontal region. Furthermore, performance on the DNMS task was correlated (in the autistic group only) with severity of autistic symptoms at the time of testing including shared attention, symbolic play, and responses to emotional stimuli (Dawson, Meltzoff, Osterling, \& Rinaldi, 1998).

In a later study, Dawson et al. (2002a) pursued their 1998 findings in a sample still younger (children aged 36-48 months), investigating the performance of autistic children, matched developmentally to two comparison groups, children with a developmental delay and normally developing children, on a series of tasks of ventromedial and dorsolateral prefrontal function. The tests of ventromedial prefrontal function employed were delayed non-matching to sample and 
Goldsmiths Research Online

object discrimination reversal. The tests of dorsolateral prefrontal function included were the Anot-B task, A-not- B with invisible displacement, and spatial reversal. Intriguingly in this study there was no autism-specific pattern of performance, suggesting that at this early age executive dysfunction is not characteristic of autism. However, performance on ventromedial (but not dorsolateral) prefrontal tasks was strongly correlated with joint attention ability. Joint attention develops rapidly from 6 to 12 months of age and its lack of presence is an early indicator of autism (e.g., Osterling \& Dawson, 1994). Indeed poor joint attention appears to be unique to, and almost totally universal in the disorder. It involves the triadic coordination or sharing of attention between the infant, another person and an object or event. Looking at another person and pointing to a cup to request a drink or looking at another person and pointing to a toy to share enjoyment are examples of this skill.

McEvoy, Rogers, and Pennington (1993) tested young autistic children (mean age 5 years) in comparison to a group of developmentally delayed children matched for age, SES, and non-verbal ability as well as to a group of normally developing children matched for SES and verbal mental age. Four well-validated tests of executive function that have been used extensively to explore prefrontal function in non-human primate studies and more recently to study the development of executive function in infants (Diamond \& Goldman-Rakic, 1986) were employed. Specifically, the A-not-B, delayed response, spatial reversal, and alternation tasks were employed in this study. An autism-specific impairment was found only on the spatial reversal task, in which the autists exhibited significantly more perseverative responses than both other groups (who did not differ from each other). Performance on each of the remaining three tasks exhibited floor or ceiling effects. Thus, young children with autism experienced selective deficits in the tests of executive function assessed by McEvoy et al., as had the older sample of preschoolers reported by Dawson et al. (1998).

Griffith, Pennington, Wehner, and Rogers (1999) pursued the line of investigation started by McEvoy et al. (1993) in two studies of young children with autism in comparison to a developmentally delayed clinical control group matched on age, verbal and non-verbal ability. In the first phase, children in both groups had a mean age of 51 months and were assessed on seven tasks of executive function (A-not-B with invisible displacement, 3- and 6 boxes stationary, 3- and 6 boxes scrambled, object retrieval, and spatial reversal). On no task were the autistic participants impaired in relation to the matched, developmentally delayed controls. In a follow-up study, a subset of the original sample was tested on the spatial reversal test one year later. In this study, the performance of neither group improved significantly over the course of one year. However, there was a trend towards an improvement in the developmentally delayed children that was not evident in the autistic group.

Interestingly, then, it has proved difficult to identify widespread executive dysfunction in prefrontal function in preschool children with autism. An overview of these four studies suggests that it is only in the older children that deficits become apparent. Perhaps, then, executive dysfunction in autism is not evident until later in life? Given the slow maturation of the frontal lobes it would not, perhaps, be surprising if this were the case. However, there is growing evidence for the influence of prefrontal cortex in the control of executive functions in infancy (Diamond, 1990, 1991; Diamond et al., 1997) and therefore the late emergence of such deficits in autism may point to certain explanations of the apparent executive dysfunction seen in older individuals with autism. There are number of explanations: For example, it could be (i) that a well-functioning prefrontal cortex undergoes deterioration in later childhood development, (ii) that prefrontal cortex is sufficient to subserve the simplest executive functions but fails to adequately mature past a given level, or (iii) that interference from elsewhere (perhaps from too many extraneous projections) expands over time. In a recent review, Frith (2003) speculated that poor pruning occurs in autism. The normal pruning process occurs several times during development after an initial wave of proliferation of synapses (Huttenlocher \& Dabholkar, 1997). Pruning eliminates faulty connections and optimises coordinated neural functioning. Lack of pruning in autism may be associated with poor functioning of certain neural circuits. For 
example, the synapses of so-called feedback (top-down) systems fail to be pruned while feedforward (bottom-up) systems are normal. Moreover, the nature of the deficit might also be expected to change over time, in line with further maturation (or lack thereof) of the relevant brain structures. It remains to be seen whether more sensitive tasks would highlight an autismspecific impairment at a young age. Certainly further study is needed, and in particular longitudinal studies tracking participants over the lifespan using comparable tests are needed. These questions are critical as since the emergence of the executive dysfunction account of autism much has been speculated about the role of the putative dysfunction in autism and in particular its causal role in the disorder (see especially papers in Russell, 1997). To date, however, it seems difficult to conclude whether or not executive dysfunction is a characteristic of the preschool autistic child. This is because normally developing children do not perform particularly well on the tests under consideration and therefore the performance of young children with autism cannot be confidently distinguished statistically in one direction or another from other groups at this age. Whether or not this provides evidence against the speculation that executive dysfunction is a primary deficit to the disorder (Ozonoff et al., 1991) remains to be seen.

\section{Executive function and the broader autism phenotype}

A small, but increasing number of studies are highlighting the existence of a broader cognitive phenotype of autism (see Bailey, Palferman, Heavey, \& Le Couteur, 1998 for a review), and these may help to elucidate the causes of autism. In essence, a broader cognitive phenotype exists when close relatives of an individual with autism show a raised incidence of cognitive performance associated with the diagnosis of autism, but to a mild degree that does not put them into the category of being diagnosed with autism themselves. A handful of studies have investigated executive functioning in the biological relatives of autistic individuals. Using the Tower of London and Intra-/extradimensional (ID/ED) shift tasks described above, Hughes, Leboyer, and Bouvard (1997) reported that the parents, and especially fathers, of children with autism showed relatively poor planning and attentional flexibility skills in comparison to both the parents of children with learning disability and children with no disorder. All groups performed equally well on a test of spatial span and on non-executive aspects of the Tower and ID/ED shift tasks, thereby ruling out an explanation of the difference in terms of ability or motivational factors. Using the same tasks Hughes, Plumet, and Leboyer (1999) identified difficulties in executive function in the nonautistic siblings of children with autism, while Ozonoff, Rogers, Farnham, and Pennington (1993) reported a similar finding in performance on a four-ring Tower of Hanoi task, and a trend towards such a significant difference on the WCST. The parents of two children with autism have been shown to be impaired in comparison to parents of children with Down Syndrome on the Tower of Hanoi task (Piven \& Palmer, 1997). Thus, evidence of a broader autism phenotype is provided in the executive domain. Aspects of the other two main cognitive theories of autism have been found in the broader phenotype providing good evidence for its existence across broad areas of its features (e.g. Baron-Cohen \& Hammer, 1997; Happé, Briskman, \& Frith, 2001). Dawson and colleagues have argued recently that executive function is one of six candidate broader autism phenotype measures for the focus of genetic studies (Dawson et al., 2002b). Integrating genetic, brain, and behavioural perspectives must be key for future progress in the understanding of autism.

\section{Autism and the frontal lobes}

Since the term executive function is a cognitive construct used to describe behaviours thought to be mediated by the frontal lobes, these structures are also referred to in relation to autism. An integration of the behavioural findings in autism and the known brain abnormalities underlying similar behaviours in patients with acquired damage to the frontal lobes of the brain, and other disorders which lead to executive dysfunction, accords well with the notion of abnormalities in the prefrontal cortex and its connections with other brain structures such the basal ganglia, striatum, and cerebellum in individuals with autism (Duncan \& Owen, 2000; Robbins, 
1997; Shallice, 1988). In a detailed behavioural study of patients with focal frontal or posterior lesions and controls matched for age, gender, education, and handedness, Stuss et al. (2000) have shown the importance of medial and dorsolateral frontal structures in the WCST. Furthermore, multi-tasking (which requires considerable numbers of executive functions) has been shown to be impaired in patients who have acquired frontal lobe damage even when an executive function deficit is small or indeed undetectable using traditional neuropsychological tests such as the WCST (Burgess, Veitch, de Lacy Costello, \& Shallice, 2000; Shallice \& Burgess, 1993). The use of neuroimaging, in combination with behavioural assessments thus allows the fractionation of brain structures. Taken together, the findings of behavioural and neuroimaging studies may help guide research in autism by suggesting parallels between neurological patients with acquired damage to the frontal lobes and some of the behavioural difficulties reported by autistic individuals. While valuable, such comparisons must be made with some caution since acquired and developmental disorders, while linked to the same neuroanatomical regions, are unlikely to be entirely similar.

Studies of the structure of the autistic brain are limited (see review by Brambilla et al., 2003). Many regions of the brain have been implicated but the neurobiological basis of the disorder remains unknown. A handful of neuroanatomical studies has reported distinct abnormalities in a number of cortical (focusing on frontal and temporal lobes and the cerebellum) and subcortical regions (focussing on the amygdala and hippocampus), but the results are inconsistent (e.g. Abell et al., 1999; Aylward et al., 1999; Bailey, Luthert et al., 1998; Bauman \& Kemper, 1994; Courchesne, Yeung-Courchesne, Press, Hesselink, \& Jernigan, 1988; Haznedar et al., 2001; Kemper \& Bauman, 1998; Pierce, Muller, Ambrose, Allen, \& Courchesne, 2001). Conclusions are hindered by the fact that abnormalities do not appear to be consistent across all brains studied. Neuroanatomical abnormalities in the limbic system and cerebellum would certainly be consistent with prefrontal damage, since all three brain areas are intimately connected (Damasio \& van Hoesen, 1983). Consistent with a frontal cortex dysfunction, transient delayed postnatal maturation of the frontal lobes has been reported (Zilbovicius et al., 1995). Serotinergic abnormalities in the prefrontal cortex (also the thalamus and dentate nucleus) have been identified in a PET study of autistic boys (Chugani et al., 1997). Finally, using single case voxelbased morphometric analysis, Salmond, de Haan, Friston, Gadian, and Vargha-Khadem (2003) report that 13 of 14 autistic children and adolescents (aged 8-18 years) showed evidence of abnormality in the orbitofrontal cortex. Structural abnormality in this area was seen in far more cases than in the other regions of interest reported (amygdala, cerebellum, hippocampal formation, and superior temporal gyrus). These regions can be accounted for from a developmental perspective, as early damage to one brain area could change the structure and function of another, with cascading effects on further development across connected structures. It remains to be seen whether further structural MRI and other neuroanatomical studies of the brains of autistic individuals will support this notion.

A number of functional neuroimaging studies of autistic behaviour have been published (see Frith, 2001 and Cody, Pelphrey, \& Piven, 2002; for recent reviews). However, only one or two of these have utilised any kind of executive function task. One exception has used functional MRI (fMRI) to investigate the performance of non-mentally retarded individuals in relation to healthy volunteers on an occulomotor spatial working memory task and a visually guided saccade task. Significantly less task-related activity was seen in dorsolateral prefrontal cortex and posterior cingulate cortex in the autistic individuals, but no other differences in activation of spatial working memory circuitry. This study suggests abnormalities in neocortical circuitry of autistic individuals (Luna et al., 2002). In addition, using fMRI Müller, Pierce, Ambrose, Allen, and Courchesne (2001) investigated the performance of eight high-functioning autistic males (mean age 28 years) in comparison to a group of eight normal males matched for age and handedness. Participants were asked to perform a simple visually paced finger movement task, which could be seen to reflect aspects of executive function involved in the planning and execution of a prompted action sequence. Neural activity during this task was compared to a control task in which identical visual stimulation was given, but no motor response was required. 
In a group analysis, activations of identical brain areas were seen in both the autistic and nonautistic individuals. Of particular interest here is the finding of reduced deactivation (that is, greater activation) in posterior and prefrontal cortices in the autism group only.

A number of explanations for the link between brain and behaviour have been raised in relation to autism and executive dysfunction. One of these has hypothesised executive dysfunction to be a consequence of abnormalities in medial temporal lobe (MTL) function, with variability in performance on executive tasks arising from the varying severity of MTL brain abnormalities (Dawson et al., 2002b). Two versions of this account place executive dysfunction as associated to, rather than causal to the core autistic symptoms. By this account, impairments in prefrontal function in older individuals with autism are secondary consequences of early MTL dysfunction, consequences that do not become apparent until the frontal lobes mature.

An alternative view is that a more direct link exists between frontal lobe abnormality and executive dysfunction. Autistic performance may be tied to dysfunctional integration of the frontal lobes with the rest of the brain, abnormal developments in neuronal sophistication and/or abnormal myelinisation (see Dawson et al., 2002b; Luna et al., 2002). Findings of transient delayed postnatal maturation of the frontal lobes in autism (Salmond et al., 2003; Zilbovicius et al., 1995) and reduced functional connectivity of frontal cortex with other cortical and subcortical regions (see Luna et al., 2002) support this view. The failure of the frontal lobes to follow a normal maturational pattern is likely to have long-term consequences for all development. This abnormality might be reflected differentially over time as the impact of abnormal development on that of other connected systems is seen. Clearly further study is needed, and in particular longitudinal studies tracking participants over their lifespan using comparable tests. Detailed functional imaging studies of tasks of executive function, as well as detailed studies of brain structure will be critical if we are to understand more appropriately the extent of executive dysfunction in the autist, and the implications of such dysfunction.

\section{Frontal lobe development and autism}

As autism is a developmental disorder, the developmental impact of damage to particular brain structures on performance must be considered more directly in the future. Given the late maturity of the frontal lobes, with the prefrontal cortex for example not being fully mature either physiologically or structurally until mid-adolescence (Diamond \& Doar, 1989; Huttenlocher \& Dabholkar, 1997; Luciana \& Nelson, 1998; Mesulam, 2002), it would be unsurprising if their development is altered in autism, since these structures are intimately connected to many of the brain areas also implicated in autism (e.g., cerebellum). The cerebellum is consistently activated during any cognitive task in which dorsolateral prefrontal cortex is activated, over and independent of any motor requirements of task (Diamond, 2000, 2002). Abnormality of development from birth would have long-term consequences for all development. This abnormality might only be reflected later in development and contrasts with breakdown in cognitive function following an acquired mental disorder that first manifests itself when the development of various abilities is completed. In this case we expect breakdown, perhaps regression or progressive deterioration, but all superimposed on previously established skills. The importance of this perspective can be seen in the two adult cases reported by Price, Daffner, Stowe, and Mesulam (1990). These two individuals suffered bilateral prefrontal damage early in life and presented later with immature development in the realms of insight, foresight, social judgement, empathy, and complex reasoning. These can be seen to reflect poor executive functioning and are reminiscent of autistic behaviour.

\section{The relationship between executive dysfunction and social impairments in autism}

Since the emergence of the executive dysfunction account of autism there has been much debate over the potential relationship between this and the theory of mind (also termed, mentalising) 
Goldsmiths Research Online

deficit account of autism. Three positions have emerged. First, it has been argued that the development of executive functions allows the child's theory of mind to develop (e.g., Ozonoff, 1997; Ozonoff et al., 1991; Russell, 1996, 1997, 2002). Second it has been argued that there are no specific systems for processing mental states and that performance on theory of mind tasks can be reduced to executive function ability (Frye, Zelazo, \& Palfai, 1995, 1996). Poor performance on a test of false belief, for example, would arise where there is a deficit in the ability to inhibit a prepotent response while holding in working memory some action- relevant information. A third position takes the opposing view of the first, arguing that the capacity to represent mental states is necessary for the development of executive function (e.g., Carruthers, 1996; Perner, 1998; Perner \& Lang, 2000). By this account, an individual must be able to represent their own intentions in order to plan ahead. Other executive functions, such as inhibitory control and set-shifting, require a representation of one's knowledge that the current act is maladaptive (Perner, 1998).

Recent research has shed some light on the possible direction of any relationship between executive functioning and mentalising. Studies that relate success and failure on particular executive function tasks to performance on theory of mind tests are critical in this regard. In normally developing preschool children, correlations have been found between tests of inhibitory control and attentional flexibility, and a test of deceit (Hughes, 1998a).Moreover, performance on tests of executive function predicts performance on theory of mind tests. The reverse association is not seen (Hughes, 1998b). These findings with normally developing children, integrated with the findings that autistic individuals perform poorly on tests of executive function as well as tests of theory of mind suggest that the difficulty that autistic individuals have on theory of mind tests is at least in part attributable to their lack of executive control. Whether this is the case in both normal and autistic development is unclear: Ozonoff et al. (1991) found a correlation between performance on executive function and theory of mind tasks in high-functioning children and adolescents with autism, but not in a matched group of developmentally delayed controls. The difficulties experienced by autistic children with inhibitory control and attentional flexibility are particularly enlightening since these are the two components of executive function that have been shown to predict theory of mind performance in normal children (Hughes, 1998a). Thus, increasingly evidence from studies of normally developing and autistic children on tests of theory of mind and executive functions are suggesting that there is a complex relationship between executive function and theory of mind.

While the data above are relevant, they are not able to distinguish between the different accounts of the developmental interaction between theory of mind and executive function. This is for two reasons. First, the complexity of tests of executive functioning is mirrored in most tests of theory of mind such that these tasks may not be 'pure' tests of theory of mind but may also involve an executive component. This has been reflected, for example, in the false photograph test (Leekam \& Perner, 1991; Leslie \& Thaiss, 1992; Russell et al., 1999b). Given this complexity, a lack of dissociation or the existence of correlations between theory of mind and executive function tasks should be expected. However, it is unlikely that we can account entirely for associations in this way since Perner and Lang (2000) report that the association between theory of mind and executive function performance is found even when theory of mind tasks that are reputed to have a low executive component are used. A second explanation of any interaction between theory of mind and executive function could arise from the anatomical proximity of the brain regions that mediate these two cognitive processes. Given the importance of prefrontal circuits in executive functions (see review by Duncan \& Owen, 2000) and the proposed role of medial frontal areas in theory of mind processing (see review by Frith \& Frith, 2003), this account of the data is not implausible.

Patients with acquired damage to the frontal lobe can also be recruited to consider the relationship between executive function and mentalising, with its implications for the possibility of frontal lobe dysfunction in autism. One patient, MR, has been reported who performs poorly on the WCST, while performing well on mentalising tasks (Varley, Siegal, \& Want, 2001). In contrast, Fine, Lumsden, and Blair (2001) have reported a case (BM) who shows the opposite profile. In 
this rigorous study, BM showed impaired performance on a range of mentalising tests in the context of intact performance on all of 16 tests of executive function administered (including the WCST, the ID/ED shift and Tower of London tasks). It is tempting to interpret these two studies as highlighting a double dissociation between the two cognitive processes. However, at this stage we should be cautious since the case of MR, with a diagnosis of severe aphasia, was assessed on only one dimension of executive function (set-shifting). Furthermore, he had sustained damage to a number of brain structures including parts of the parietal lobe, as well as subcortical damage to association fibres running between posterior sensory zones and the frontal lobe. This patient's poor performance on the WCST, which has a large visuospatial component, may be accounted for by this damage (see Stuss et al., 2000). Further detailed testing of MR, and other patients is required.

Studies have also been reported of patients with acquired brain damage who perform poorly on tests of both executive function and theory of mind. Rowe, Bullock, Polkey, and Morris (2001) observed that patients with unilateral right- or left-frontal lobe lesions performed badly on both mentalising tasks and executive tasks. (The latter assessed initiation, inhibition, mentalflexibility, and sequencing.) Gregory et al. (2002) reported similar results in cases of frontal variant frontotemporal dementia. (Executive function was assessed using the WCST and a verbal fluency test.) Statistical analyses in both studies are reported to indicate that poor performance in one cognitive domain was not related to poor performance in the other cognitive domain.

Combined, these various approaches to understanding the relationship between two key cognitive explanations of autism highlight the complexity of any relationship. In particular, clarity is hampered by the use of different samples and tests, and different causes of brain damage (acquired but isolated vs. developmental vs. dementia). More detailed understanding of the brain-behaviour relationship of each component of executive functions will provide clearer hypotheses on which to work. It will be useful in the future to pursue more studies of the 'normal' and 'abnormal' brain of the kind reported by Stuss et al. (2000). These authors conducted a validation of the relationship between the WCST and 'frontal functions' by careful analysis of patients with brain disease. A similar study using an experimental task reported recently by Sylvester et al. (2003) is a further example. Both studies provide evidence that executive processes are distinct from one another but nonetheless work together in order to meet a particular common goal. Thus, executive functioning is a complex multifactorial cognitive construct and can be seen to be composed of both common and distinct mechanisms. It is not one unitary process that is implemented to complete any one task. Common selective attention mechanisms may be initiated but the actual manipulation of information attended to may be carried out by different neural areas that implement different executive functions such as the switching of attention and the resolution of interference. Understanding how these cognitive processes interact to implement executive control will be a central challenge for future research. The study of the structure of the frontal lobes of the autistic brain, as well as brain activation patterns in the autistic brain while tasks of executive function are being performed will inform this relationship, and vice versa.

\section{Problems with the executive function account of autism}

There is thus clear evidence that individuals with autism experience deficits in areas of executive functioning, and this cognitive theory has gained much ground in recent years. However, there are some problems with this account. One difficulty arises from a lack of consensus as to which aspects of executive function are typical of autism. Another comes from the rather restricted age and ability ranges of the samples assessed. A perhaps more striking difficulty arises from the fact that executive dysfunction is found in clinical conditions other than autism (e.g., attention deficit hyperactivity disorder; ADHD). Certainly this problem limits the potential to use executive dysfunction as a diagnostic marker for autism. It may be that this difficulty will be resolved in the light of future detailed work investigating executive functions in autism. A useful example of such 
an approach is found in Ozonoff and Jensen (1999) who assessed three groups of children with a clinical condition believed to be associated with executive dysfunction (autism, ADHD, and Tourette syndrome) as well as a normally developing control group. The groups were matched for chronological age and full-scale IQ. All participants completed a test of planning (Tower of Hanoi), cognitive set-shifting (Wisconsin Card Sorting test), and a test of inhibition (Stroop test). Differential performance between the groups was found across the executive function tasks. Specifically, children with autism were the only clinical group impaired in relation to all three other groups on both the test of planning and cognitive flexibility. In contrast, the children with ADHD alone were impaired relative to the two clinical and the normal control groups on the test of inhibition. This study suggests that there is a specific pattern of executive dysfunction that distinguishes autism from other developmental disorders associated with executive dysfunction. A recent selective review of literature considering whether executive function deficits are specific to ADHD, in which studies of ADHD, oppositional defiant disorder (ODD), conduct disorder (CD), and autism are compared, suggests that while these disorders are all associated with executive function deficits, there are strong differences between these groups and normally developing individuals in executive functioning (Sergeant et al., 2002). Thus, specific executive performance profiles differentiate between these clinical groups. However, a recent study has shown a less clear difference in planning ability between boys with a diagnosis of either autism or ADHD. Booth et al. (2003) used a drawing task in which planning for the inclusion of a new element was measured. Planning deficits were seen in their sample of boys with autism as well as those with ADHD, in comparison to typically developing children. These difficulties were more noticeable in the autism group. Clearly, detailed studies of executive functioning in different clinical populations associated with executive function deficits are needed. If such studies support a specific but differential profile of executive dysfunction in these disorders then the possibility will arise of using measures of executive function as a marker for the diagnosis of autism.

A further difficulty with the executive dysfunction account of autism is that, while such difficulties appear to be common, they may not be a universal feature of autism. Certain studies have found that the tests of executive function that they have employed have not been problematic for all autistic individuals with normal IQ levels (Baron-Cohen, Wheelwright, Stone, \& Rutherford, 1999; Russell \& Hill, 2001; Hill \& Russell, 2002). However, as yet, the universality of executive dysfunction in autism cannot be ruled out. Looking to the neuropsychological literature can provide some possible directions for future investigation of the universality of executive dysfunction in autism. Studies of certain patients with acquired damage to the frontal lobes show unique deficits in multitasking along side little or no impairment on measures of executive function such as Tower and WCST tasks. However these patients, first reported by Shallice and Burgess (1991), show marked impairments in everyday life. These patients have been described as having a 'strategy application disorder,' a specific deficit in multitasking, which includes planning, and retrospective memory, prospective memory (see Burgess et al., 2000 for full discussion of multitasking). Examples of tests of multitasking are the Multiple Errands task (Shallice \& Burgess, 1991), the Six Elements subtest of the BADS (Wilson, Alderman, Burgess, Emslie, \& Evans, 1996) or the related Greenwich test (Burgess et al., 2000). In these tests participants are presented with a series of tasks that they must attempt within a specified time frame. They are also given a number of rules that they must follow in order to complete the test correctly, that they must not complete two parts of the same activity consecutively for example. Not only are such patients impaired on tests of multitasking, but their performance on the Six Elements task has been shown to correlate highly with their relative or carer's assessment of their difficulty in realising plans in daily life. A similar association was not seen between daily life skill and other tests of executive function (Shallice \& Burgess, 1996). It seems likely that such subtle yet striking impairments may also be seen in autistic individuals with normal IQ levels who are not, as yet, considered to have an executive function deficit. At the Institute of Cognitive Neuroscience, we are conducting just such a study, assessing traditional neuropsychological tests of executive function such as the WCST and the Stroop test alongside a range of tests more sensitive to executive deficits clearly seen in daily life such as the Six Elements test. The results of this study will be forthcoming shortly. 
Goldsmiths Research Online

What is the influence of general ability on executive functioning? At this stage it is unclear how great the impact of the presence/absence of a learning disability is on the executive functioning of the autistic groups studied. It is certainly the case that adult studies of executive function tend to focus only on individuals with an IQ above 85 (i.e., within the normal range). The question must therefore be addressed by assessing autistic individuals whose IQs fall within the normal range in comparison to appropriate control groups. This question is becoming more and more pertinent as increasing numbers of people with Asperger syndrome (considered to be a form of highfunctioning autism) are being diagnosed. These individuals have IQs well within the normal range, they tend to have been educated in mainstream schools and may even be diagnosed only in adulthood. Yet they experience striking difficulties in the core areas of autistic dysfunction. Anecdotally these difficulties relate very much to the executive domain. The results of our ongoing study, mentioned above, will help to identify the pattern of executive functioning in autism as well as its universality. This understanding has the potential to impact positively on the remediation of real-life deficits in executive function, for example, to strengthen planning and organisational strategies by teaching skills to shift from ineffective planning strategies.

\section{Final comments}

Before concluding this review of executive function, the value of the overall approach in understanding autism should be considered. Given the contradictory findings, the apparent difficulty in identifying whether executive deficits exist in young children with autism, and the reported lack of universality of executive dysfunction in laboratory tests, one might be tempted to conclude that the theory has little to contribute to our understanding of autistic disorder. However, the theory is far from ready to be dropped as one of the key cognitive theories of the condition. Research in this area is still in its infancy, and needs to be further informed in the future by advances in understanding of the normal development and function of the frontal lobes as well as understanding of the neuropsychological findings. Given the, albeit anecdotal, sense of executive impairments in daily life in autistic individuals, it may be time to focus on a more cognitive and neuroanatomical framework of executive systems, and use this model to guide investigations in the future. One perspective on disorders of executive systems is that they result from damage to a higher level supervisory system. Following Norman and Shallice (1986), Shallice and Burgess (e.g. Shallice, 2002; Shallice \& Burgess, 1996) have outlined a cognitive model of executive function, centred on the frontal lobes and particularly on prefrontal cortex, in which a higher-order system - the Supervisory System-is responsible for control of non-routine operations (clearly involved in tasks such the Tower of London and WCST) and a contention scheduler is involved in carrying out routine operations. By assessing tasks that would be predicted to be controlled by one or other of these systems within the same sample, it may be possible to fractionate the high-level executive system and its dysfunction in autism. Furthermore, by considering performance on a wide range of tasks, with clear stages of progression (such as the ID/ED shift task) and tightly matched control tasks (such as the inhibition studies of Ozonoff et al.) in well-matched participant groups it will be possible to establish clearer performance profiles of executive function. Furthermore, by fractionating the high-level executive system and by being able to make neuropsychological and neuroanatomical parallels, significant progress in understanding executive functioning in autism should now be possible. Finally, the developmental pattern of executive dysfunction in autism remains unclear and will benefit from detailed longitudinal study across the lifespan.

\section{Acknowledgments}

This work was completed while the author worked at the Institute of Cognitive Neuroscience, University College London. It was supported by funding from the Medical Research Council (UK) to Uta Frith (Grant number G9716841) and facilitated by the MRC Cooperative at the Institute of Cognitive Neuroscience. My thanks to members of the Developmental Disorders and Executive 
Goldsmiths Research Online

Functions research groups at the Institute of Cognitive Neuroscience, in particular to Uta Frith, Sarah White, and Chris Bird.

\section{References}

Abell, F., Krams, M., Ashburner, J., Passingham, R., Friston, K., Frakowiak, R., Happ_e, F., Frith, C., \& Frith, U. (1999). The neuroanatomy of autism: A voxel-based whole brain analysis of structural scans. Neuroreport, 10, 1647-1651.

Anderson, V., Levin, H. S., \& Jacobs, R. (2002). Executive functions after frontal lobe injury:

A developmental perspective. In D. T. Stuss \& R. T. Knight (Eds.), Principles of frontal lobe function (pp. 504-527). Oxford: Oxford University Press.

Army Individual Test Battery (1944). Manual of Directions and Scoring. Washington DC: War Department, Adjutant General's Office.

Aylward, E. H., Minshew, N. J., Goldstein, G., Honeycutt, N. A., Augustine, A. M., Yates, K. O., Barta, P. E., \& Pearlson, G. D. (1999). MRI volumes of amygdala and hippocampus in non-mentally retarded autistic adolescents and adults. Neurology, 53, 2145-2150.

Bailey, A., Luthert, P., Dean, A., Harding, B., Janota, I., Montgomery, M., Rutter, M., \& Lantos, P. (1998). A clinicopathological study of autism. Brain, 121, 889-905.

Bailey, A., Palferman, S., Heavey, L., \& Le Couteur, A. (1998). Autism: The phenotype in relatives. Journal of Autism and Developmental Disorders, 28, 369-392.

Baird, G., Charman, T., Baron-Cohen, S., Cox, A., Swettenham, J., Wheelwright, S., \& Drew, A. (200o). A screening instrument for autism at 18 months of age: A 6 year follow-up study. Journal of the American Academy for Child and Adolescent Psychiatry, 39, 694-702.

Baron-Cohen, S. (2002). The extreme male brain theory of autism. Trends in Cognitive Sciences, 6, 248254 .

Baron-Cohen, S., \& Hammer, J. (1997). Parents of children with Asperger syndrome: What is the cognitive phenotype? Journal of Cognitive Neuroscience, 9, 548-554.

Baron-Cohen, S., Tager-Flusberg, H., \& Cohen, D. J. (2000). Understanding other minds. Perspectives from developmental cognitive neuroscience. Oxford: Oxford University Press.

Baron-Cohen, S., Wheelwright, S., Stone, V., \& Rutherford, M. (1999). A mathematician, a physicist and a computer scientist with Asperger syndrome: Performance on psychology and folk physics tests. Neurocase, $5,475-483$.

Bauman, M. L., \& Kemper, K. L. (1994). Neuroanatomical observations of the brain in autism. In M. L. Bauman \& K. L. Kemper (Eds.), The neurobiology of autism (pp. 119-145). Baltimore: The Johns Hopkins University Press.

Bennetto, L., Pennington, B. F., \& Rogers, S. J. (1996). Intact and impaired memory functions in autism. Child Development, 67, 1816-1835.

Bíro, S., \& Russell, J. (2001). The execution of arbitrary procedures by children with autism. Development and Psychopathology, 13, 97-110.

Bishop, D. V. M., \& Norbury, C. F. (2002). Exploring the borderlands of autistic disorder and specific language impairment: A study using standardised diagnostic instruments. Journal of Child Psychology and Psychiatry, 43, 917-929. 
Goldsmiths Research Online

Bishop, D. V. M., Aamodt-Leeper, G., Creswell, C., McGurk, R., \& Skuse, D. H. (2001). Individual differences in cognitive planning on the Tower of Hanoi task: Neuropsychological maturity or measurement error? Journal of Child Psychology and Psychiatry, 42, 551-556.

Booth, R., Charlton, R., Hughes, C., \& Happé, F. (2003). Disentangling weak coherence and executive dysfunction: Planning drawing in autism and attention-deficit/hyperactivity disorder. Philosophical Transactions of The Royal Society Series B, 358, 387-392.

Boucher, J. (1988). Word fluency in high-functioning autistic children. Journal of Autism and Developmental Disorders, 18, 637-645.

Brambilla, P., Hardan, A., Ucelli di Nemi, S., Perez, J., Soares, J. C., \& Barale, F. (2003). Brain anatomy and development in autism: Review of structural MRI studies. Brain Research Bulletin, 61, 557-569.

Burgess, P. W., Veitch, E., de Lacy Costello, A., \& Shallice, T. (2000). The cognitive and neuroanatomical correlates of multitasking. Neuropsychologia, 38, 848-863.

Carruthers, P. (1996). Autism as mindblindness: An elaboration and partial defence. In P. Carruthers \& P. K. Smith (Eds.), Theories of theories of mind (pp. 257-273). Cambridge: Cambridge University Press.

Chakrabarti, S., \& Fombonne, E. (2001). Pervasive developmental disorders in preschool children. Journal of the American Medical Association, 285, 3093-3099.

Chugani, D. C. (1994). Positron emission tomography study of human brain functional development. In M. H. Johnson (Ed.), Brain development and cognition (pp. 125-143). Oxford: Blackwell.

Chugani, D. C., Muzik, O., Rothermel, R., Behen, M., Chakraborty, P., Mangner, T., da Silva, E. A., \& Chugani, H. T. (1997). Altered serotonin synthesis in the dentatothalamocortical pathway in autistic boys. Annals of Neurology, 42, 666-669.

Cody, H., Pelphrey, K., \& Piven, J. (2002). Structural and functional magnetic resonance imaging of autism. International Journal of Developmental Neuroscience, 766, 1-18.

Courchesne, E., Yeung-Courchesne, R., Press, G. A., Hesselink, J. R., \& Jernigan, T. L. (1988). Hypoplasia of cerebellar vermal lobule-Vi and lobule-Vii in autism. New England Journal of Medicine, 318, 1349-1354.

Croen, L. A., Grether, J. K., Hoogstrate, J., \& Selvin, S. (2002). The changing prevalence of autism in California. Journal of Autism and Developmental Disorders, 32, 207-215.

Damasio, A. R., \& van Hoesen, G. W. (1983). Emotional disturbances associated with focal lesions of the limbic frontal lobe. In K. M. Heilman \& P. Satz (Eds.), The neuropsychology of human emotion (pp. 85110). New York: Guildford Press.

Davidson, M., Cruess, L., Diamond, A., O’Craven, K.M., \& Savoy, R.L. (1999). Comparison of executive functions in children and adults using directional Stroop tasks. Presented at the Biennial Meeting of the Society for Research in Child Development, Albuquerque, NM, April 1999.

Dawson, G., Meltzo., A. N., Osterling, J., \& Rinaldi, J. (1998). Neuropsychological correlates of early symptoms of autism. Child Development, 69, 1276-1285.

Dawson, G., Munson, J., Estes, A., Osterling, J., McPartland, J., Toth, K., Carver, L., \& Abbott, R. (2002a). Neurocognitive function and joint attention ability in young children with autism spectrum disorder versus developmental delay. Child Development, 73, 345-358.

Dawson, G., Webb, S., Schellenberg, G. D., Dager, S., Friedman, S., Aylward, E., \& Richards, T. (2002b). Defining the broader phenotype of autism: Genetic, brain and behavioral perspectives. Development and Psychopathology, 14, 581-611.

Diamond, A. (1988). Differences between adult and infant cognition: Is the crucial variable presence or absence of language?. In L. Weiskrantz (Ed.), Thought without language (pp. 337-370). Oxford: Oxford University Press. 
Goldsmiths Research Online

Diamond, A. (1990). Developmental time course in human infants and infant monkeys, and the neural bases, of inhibitory control in reaching. Annals of the New York Academy of Sciences, 608, 637-676.

Diamond, A. (1991). Neuropsychological insights in to the meaning of object concept development. In S. Carey \& R. Gelman (Eds.), The epigenesis of mind: Essays on biology and cognition (pp. 67110). Hillsdale, NJ: Lawrence Erlbaum Associates.

Diamond, A. (2000). Close interrelation of motor development and cognitive development and of the cerebellum and prefrontal cortex. Child Development, 71 (special issue: New directions for child development in the 21st century), 44-56.

Diamond, A. (2002). Normal development of prefrontal cortex from birth to young adulthood: Cognitive functions, anatomy and biochemistry. In D. T. Stuss \& R. T. Knight (Eds.), Principles of frontal lobe function (pp. 466-503). Oxford: Oxford University Press.

Diamond, A., \& Doar, B. (1989). The performance of human infants on a measure of frontal cortex function, the delayed response task. Developmental Psychobiology, 22, 271-294.

Diamond, A., \& Goldman-Rakic, P. S. (1986). Comparative development in human infants and infant rhesus monkeys of cognitive functions on prefrontal cortex. Society for Neuroscience Abstracts, 12, 742.

Diamond, A., \& Taylor, C. (1996). Development of an aspect of executive control: Development of the abilities to remember what I said and to "do as I say, not as I do". Developmental Psychobiology, 29, 315-334.

Diamond, A., Prevor, M., Callender, G., \& Druin, D. P. (1997). Prefrontal cortex cognitive deficits in children treated early and continuously for PKU. Monographs of the Society for Research in Child Development, 62, Monograph, 252, 1-207.

Duncan, J., \& Owen, A. M. (2000). Common regions of the human frontal lobe recruited by diverse cognitive demands. Trends in Neurosciences, 23, 475-483.

Eskes, G. A., Bryson, S. E., \& McCormick, T. A. (1990). Comprehension of concrete and abstract words in autistic children. Journal of Autism and Developmental Disorders, 20, 61-73.

Fine, C., Lumsden, J., \& Blair, R. J. R. (2001). Dissociation between 'theory of mind' and executive functions in a patient with early left amygdala damage. Brain, 124, 287-298.

Fischer, B., Biscaldi, M., \& Gezeck, S. (1997). On the development of voluntary and reflexive components in human saccade generation. Brain Research, 754, 285-297.

Frith, C. D. (2003). What do imaging studies tell us about the neural basis of autism. In M. Rutter (Ed.), Autism: Neural basis and treatment possibilities. Novartis Foundation. Chichester: Wiley.

Frith, U. (2001). Mindblindness and the brain in autism. Neuron, 32, 969-979.

Frith, U., \& Frith, C. D. (2003). Development and neurophysiology of mentalizing. Philosophical Transactions of The Royal Society Series B, 358, 459-473.

Frith, U., \& Hermelin, B. (1969). The role of visual and motor cues for normal, subnormal and autistic children. Journal of Child Psychology and Psychiatry, 10, 153-163.

Frye, D., Zelazo, P. D., \& Palfai, T. (1995). Theory of mind and rule-based reasoning. Cognitive Development, $10,483-527$.

Frye, D., Zelazo, P. D., Brooks, P. J., \& Samuels, M. C. (1996). Inference and action in early causal reasoning. Developmental Psychology, 32, 120-131.

Gerstadt, C., Hong, Y., \& Diamond, A. (1994). The relationship between cognition and action: Performance of 3.5-7 year old children on a Stroop-like day-night test. Cognition, 53, 129-153. 
Goldsmiths Research Online

Giedd, J. N., Blumenthanl, J., Je.ries, N. O., Castellanos, F. X., Liu, H., Zijdenbos, A., Paus, T., Evans, A. C., \& Rapoport, J. L. (1999). Brain development during childhood and adolescence: A longitudinal MRI study. Nature Neuroscience, 2, 861-863.

Giedd, J., Snell, J., Lange, N., Rajapaske, J., Casey, B., Kozuch, P., Vaitus, A., Vauss, Y., Hamburger, S., Kaysen, D., \& Rapoport, J. (1996). Quantitative magnetic resonance imaging of human brain development: Ages 4-18. Cerbral Cortex, 6, 551-560.

Goldman-Rakic, P. S. (1987). Development of cortical circuitry and cognitive function. Child Development, 58, 601-622.

Gregory, C., Lough, S., Stone, V., Erzinclioglu, S., Martin, L., Baron-Cohen, S., \& Hodges, J. R. (2002). Theory of mind in patients with frontal variant frontotemporal dementia and Alzheimer's disease: Theoretical and practical implications. Brain, 125, 752-764.

Gri.th, E. M., Pennington, B. F., Wehner, E. A., \& Rogers, S. J. (1999). Executive functions in young children with autism. Child Development, 70, 817-832.

Happé, F. (1999). Autism: Cognitive deficit or cognitive style? Trends in Cognitive Sciences, 3, 216-222.

Happé, F., Briskman, J., \& Frith, U. (2001). Exploring the cognitive phenotype of autism: Weak central coherence in parents and siblings of children with autism: I. Experimental tests. Journal of Child Psychology and Psychiatry, 42, 299-307.

Haznedar, M. M., Buchsbaum, M. S., Wei, T. C., Hof, P. R., Cartwright, C., Bienstock, C., \& Hollander, E. (2001). Limbic circuitry in patients with autism spectrum disorders studies with positron emission tomography and magnetic resonance imaging. American Journal of Psychiatry, 157, 1994-2001.

Heaton, R. K., Chelune, G. J., Talley, J. L., Kay, G. G., \& Curtiss, G. (1993). Wisconsin Card Sorting Test manual: Revised and expanded. Odessa, FL: Psychological Assessment Resources.

Hermelin, B., \& O’Connor, N. (1975). Location and distance estimates by blind and sighted children. Quarterly Journal of Experimental Psychology, 27, 295-301.

Hill, E. L., \& Russell, J. (2002). Action memory and self-monitoring in children with autism: Self versus other. Infant and Child Development, 11, 159-170.

Hood, B. M. (1995). Gravity rules for 2-4 year olds? Cognitive Development, 10, 577-598.

Hughes, C. (1996). Brief report: Planning problems in autism at the level of motor control. Journal of Autism and Developmental Disorders, 26, 99-107.

Hughes, C. (1998a). Executive function in preschoolers: Links with theory of mind and verbal ability. British Journal of Developmental Psychology, 16, 233-253.

Hughes, C. (1998b). Finding your marbles: Does preschoolers' strategic behavior predict later understanding of mind? Developmental Psychology, 34, 1326-1339.

Hughes, C., \& Russell, J. (1993). Autistic children's difficulty with mental disengagement from an object: Its implications for theories of autism. Developmental Psychology, 29, 498-510.

Hughes, C., Russell, J., \& Robbins, T. W. (1994). Evidence for executive dysfunction in autism. Neuropsychologia, 32, 477-492.

Hughes, C., Leboyer, M., \& Bouvard, M. (1997). Executive function in parents of children with autism. Psychological Medicine, 27, 209-220.

Hughes, C., Plumet, M.-H., \& Leboyer, M. (1999). Towards a cognitive phenotype for autism: Increased prevalence of executive dysfunction and superior spatial span amongst siblings of children with autism. Journal of Child Psychology and Psychiatry, 40, 705-718. 
Goldsmiths Research Online

Huttenlocher, P. R. (1979). Synaptic density in human frontal cortex-developmental changes and effects of aging. Brain Research, 163, 195-205.

Huttenlocher, P. R. (1990). Morphometric study of human cerebral cortex development. Neuropsychologia, 28, 517-527.

Huttenlocher, P. R., \& Dabholkar, A. S. (1997). Regional differences in synaptogenesis in human cerebral cortex. Journal of Comparative Neurology, 387, 167-178.

Jarrold, C., Boucher, J., \& Smith, P. K. (1996). Generativity deficits in pretend play in autism. British Journal of Developmental Psychology, 14, 275-300.

Kemper, K. L., \& Bauman, M. L. (1998). Neuropathology of infantile autism. Journal of Neuropathology and Experimental Neurology, 57, 645-652.

Kochanska, G., Murray, K. T., \& Harlan, E. T. (2000). Effortful control in early childhood: Continuity and change, antecedents, and implications for social development. Developmental Psychology, 35, $220-232$.

Leekam, S., \& Perner, J. (1991). Does the autistic child have a metarepresentational deficit? Cognition, 40, 203-218.

Leslie, A. M., \& Thaiss, L. (1992). Domain specificity in conceptual development: Evidence from autism. Cognition, 43, 225-251.

Levin, H. S., Culhane, K. A., Hartmann, J., Evankovich, K., \& Mattson, A. J. (1991). Developmental changes in performance on tests of purported frontal lobe functioning. Developmental Neuropsychology, 7, 377-395.

Lewis, V., \& Boucher, J. (1991). Skill, content and generative strategies in autistic children's drawings. British Journal of Developmental Psychology, 9, 393-416.

Liss, M., Harel, B., Fein, D., Allen, D., Dunn, M., Feinstein, C., Morris, R., Waterhouse, L., \& Rapin, I. (2001). Predictors and correlates of adaptive functioning in children with developmental disorders. Journal of Autism and Developmental Disorders, 31, 219-230.

Lowe, C., \& Rabbitt, P. (1998). Test/retest reliability of the CANTAB and ISPOCD

neuropsychological batteries: Theoretical and practical issues. Neuropsychologia, 36, 915-923.

Luciana, M., \& Nelson, C. A. (1998). The functional emergence of prefrontally guided working memory systems in four- to eight-year-old children. Neuropsychologia, 36, 273-293.

Luna, B., Minshew, N. J., Garver, K. E., Lazar, N. A., Thulborn, K. R., Eddy, W. F., \& Sweeney, J. A. (2002). Neocortical system abnormalities in autism. An fMRI study of spatial working memory. Neurology, 59, 834840 .

McEvoy, R. E., Rogers, S. J., \& Pennington, B. F. (1993). Executive function and social communication deficits in young autistic children. Journal of Child Psychology and Psychiatry, 34, 563-578.

Mari, M., Castiello, U., Marks, D., Marraffa, C., \& Prior, M. (2003). The reach-to-grasp movement in children with autism spectrum disorder. Philosophical Transactions of The Royal Society Series B, $358,393-403$.

Mesulam, -M. (2002). The human frontal lobes: Transcending the default mode through contingent encoding. In D. T. Stuss \& R. T. Knight (Eds.), Principles of frontal lobe function (pp. 8-30). Oxford: Oxford University Press.

Milner, B. (1965). Visually-guided maze learning in man: Effects of bilateral hippocampal, bilateral frontal, and unilateral cerebral lesions. Neuropsychologia, 3, 317-338. 
Goldsmiths Research Online

Minshew, N. J., Goldstein, G., Muenz, L. R., \& Payton, J. (1992). Neuropsychological functioning in nonmentally retarded autistic individuals. Journal of Clinical and Experimental Neuropsychology, $14,749-761$.

Minshew, N. J., Goldstein, G., \& Seigel, D. J. (1995). Speech and language in high-functioning autistic individuals. Neuropsychology, 9, 255-261.

Müller, -A., Pierce, K., Ambrose, J. B., Allen, G., \& Courchesne, E. (2001). Atypical patterns of cerebral motor activation in autism: A functional magnetic resonance study. Biological Psychiatry, 49, 665-676.

Nelson, H. E. (1976). A modified card sorting test sensitive to frontal lobe defects. Cortex, 12, 313-324.

Norman, D. A., \& Shallice, T. (1986). Attention to action: Willed and automatic control of behaviour. In G. E. Schwartz \& D. Shapiro (Eds.), Consciousness and self-regulation (Vol. 4, pp. 1-18). New York: Plenum Press.

Nyden, A., Gillberg, C., Hjelmquist, E., \& Heiman, M. (1999). Executive/attention deficits in boys with Asperger syndrome, attention disorder and reading/writing disorder. Autism, 3, 213-228.

Osterling, J., \& Dawson, G. (1994). Early recognition of children with autism: A study of first birthday home videotapes. Journal of Autism and Developmental Disorders, 24, 247-257.

Ozonoff, S. (1995). Reliability and validity of the Wisconsin Card Sorting Test in studies of autism. Neuropsychology, 9, 491-500.

Ozonoff, S. (1997). Components of executive function in autism and other disorders. In J. Russell (Ed.), Autism as an executive disorder (pp. 179-211). Oxford: Oxford University Press.

Ozonoff, S., \& Jensen, J. (1999). Brief report: Specific executive function profiles in three neurodevelopmental disorders. Journal of Autism and Developmental Disorders, 29, 171-177.

Ozonoff, S., \& McEvoy, R. E. (1994). A longitudinal study of executive function and theory of mind development in autism. Development and Psychopathology, 6, 415-431.

Ozonoff, S., \& Strayer, D. L. (1997). Inhibitory function in nonretarded children with autism. Journal of Autism and Developmental Disorders, 27, 59-77.

Ozonoff, S., Pennington, B. F., \& Rogers, S. J. (1991). Executive function deficits in high-functioning autistic individuals: Relationship to theory of mind. Journal of Child Psychology and Psychiatry, 32, 1081-1105.

Ozonoff, S., Rogers, S. J., Farnham, J. M., \& Pennington, B. F. (1993). Can standard measures identify subclinical markers of autism. Journal of Autism and Developmental Disorders, 23, 429-441.

Ozonoff, S., Strayer, D. L., McMahon, W. M., \& Filloux, F. (1994). Executive function abilities in autism and Tourette syndrome: An information-processing approach. Journal of Child Psychology and Psychiatry, 35, $1015-1032$.

Pennington, B. F., \& Ozonoff, S. (1996). Executive functions and developmental psychopathology. Journal of Child Psychology and Psychiatry, 37, 51-87.

Perner, J. (1998). The meta-intentional nature of executive functions and theory of mind. In P. Carruthers \& J. Boucher (Eds.), Language and thought: Interdisciplinary themes (pp. 270-316). Cambridge: Cambridge University Press.

Perner, J., \& Lang, B. (2000). Theory of mind and executive function: Is there a developmental relationship. In S. Baron-Cohen, T. Tager-Flusberg, \& D. Cohen (Eds.), Understanding other minds: Perspectives from developmental cognitive neuroscience (pp. 150-181). Oxford: Oxford University Press.

Phillips, W., Baron-Cohen, S., \& Rutter, M. (1998). Understanding intention in normal development and autism. British Journal of Developmental Psychology, 16, 337-348. 
Goldsmiths Research Online

Piaget, J. (1954 [1936]). The construction of reality in the child., (M. Cook trans.) New York: Basic Books.

Pierce, K., Muller, R. A., Ambrose, J., Allen, G., \& Courchesne, E. (2001). Face processing occurs outside the fusiform 'face area' in autism: Evidence from functional MRI. Brain, 124, 2059-2073.

Piven, J., \& Palmer, P. (1997). Cognitive deficits in parents from multiple-incidence autism families. Journal of Child Psychology and Psychiatry, 38, 1011-1021.

Price, B. H., Daffner, K. R., Stowe, R. M., \& Mesulam, M. M. (1990). The comportmental learning disabilities of early frontal lobe damage. Brain, 113, 1383-1393.

Prior, M. R., \& Hoffmann, W. (1990). Brief report: Neuropsychological testing of autistic children through an exploration with frontal lobe tests. Journal of Autism and Developmental Disorders, 20, 581-590.

Rabbitt, P. (1997). Methodology of frontal and executive function. Hove: Psychology Press.

Robbins, T. W. (1997). Integrating the neurobiological and neuropsychological dimensions of autism. In J. Russell (Ed.), Autism as an executive disorder (pp. 21-53). Oxford: Oxford University Press.

Roberts, A. C., Robbins, T. W., \& Weiskrantz, L. (1998). The prefrontal cortex. Executive and cognitive functions. Oxford: Oxford University Press.

Rowe, A. D., Bullock, P. R., Polkey, C. E., \& Morris, R. G. (2001). 'theory of mind' impairments and their relationship to executive functioning following frontal lobe excisions. Brain, 124, 600-616.

Rumsey, J. M. (1985). Conceptual problem-solving in highly verbal, nonretarded autistic men. Journal of Autism and Developmental Disorders, 15, 23-36.

Rumsey, J. M., \& Hamburger, S. D. (1988). Neuropsychological findings in high-functioning men with infantile autism. Journal of Autism and Developmental Disorders, 20, 155-168.

Rumsey, J. M., \& Hamburger, S. D. (1990). Neuropsychological divergence of high-level autism and severe dyslexia. Journal of Autism and Developmental Disorders, 20, 155-168.

Russell, J. (1996). Hove: Erlbaum (UK), Taylor \& Francis.

Russell, J. (1997). How executive disorders can bring about an adequate theory of mind. In J. Russell (Ed.), Autism as an executive disorder (pp. 256-304). Oxford: Oxford University Press.

Russell, J. (2002). Cognitive theories of autism. In J. E. Harrison \& A. M. Owen (Eds.), Cognitive deficits in brain disorders (pp. 295-323). London: Martin Dunitz.

Russell, J., \& Hill, E. L. (2001). Action-monitoring and intention reporting in children with autism. Journal of Child Psychology and Psychiatry, 42, 317-328.

Russell, J., \& Jarrold, C. (1998). Error-correction problems in autism: Evidence for a monitoring impairment. Journal of Autism and Developmental Disorders, 28, 177-188.

Russell, J., \& Jarrold, C. (1999). Memory for actions in children with autism: Self versus other. Cognitive Neuropsychiatry, 4, 303-331.

Russell, J., Jarrold, C., \& Hood, B. (1999a). Two intact executive capacities in children with autism: Implications for the core executive dysfunctions in the disorder. Journal of Autism and Developmental Disorders, 29, 103-112.

Russell, J., Hala, S., \& Hill, E. L. (2003). Mechanising an executive task: The performance of preschool children, children with autism and with moderate learning difficulties in the automated Windows Task. Cognitive Development, 18, 111-137.

Russell, J., Saltmarsh, R., \& Hill, E. L. (1999b). Do executive factors contribute to the failure of false belief tasks of children with autism? Journal of Child Psychology and Psychiatry, 40, 859-868. 
Goldsmiths Research Online

Russell, J., Mauthner, N., Sharpe, S., \& Tidswell, T. (1991). The 'Windows task' as a measure of strategic deception in preschoolers and autistic subjects. British Journal of Developmental Psychology, 9, $101-119$.

Salmond, C. H., de Haan, M., Friston, K. J., Gadian, D. G., \& Vargha-Khadem, F. (2003). Investigating individual differences in brain abnormalities in autism. Philosophical Transactions of The Royal Society Series B, 358, 405-413.

Scott, F., \& Baron-Cohen, S. (1996). Imagining real and unreal things: Evidence of a dissociation in autism. Journal of Cognitive Neuroscience, 8, 371-382.

Sergeant, J. A., Geurts, H., \& Oosterlaan, J. (2002). How specific is a deficit of executive functioning for attention-deficit/hyperactivity disorder? Behavioural Brain Research, 130, 3-28.

Shallice, T. (1988). From neuropsychology to mental structure. Cambridge: Cambridge University Press.

Shallice, T. (2002). Fractionation of the supervisory system. In D. T. Stuss \& R. T. Knight (Eds.), Principles of frontal lobe function (pp. 261-277). Oxford: Oxford University Press.

Shallice, T., \& Burgess, P. W. (1991). Deficits in strategy application following frontal lobe damage in man. Brain, 114, 727-741.

Shallice, T., \& Burgess, P. W. (1993). Supervisory control of action and thought selection. In A. D. Baddeley \& L. Weiskrantz (Eds.), Attention: Selection, awareness and control: A tribute to Donald Broadbent (pp. 171187). Oxford: Oxford University Press.

Shallice, T., \& Burgess, P. W. (1996). The domain of supervisory processes and temporal organisation of behaviour. Philosophical Transactions of the Royal Society Series B, 351, 1405-1412.

Shu, -C., Lung, -W., Tien, A. Y., \& Chen, -C. (2001). Executive function deficits in non-retarded autistic children. Autism, 5, 165-174.

Sowell, E. R., Thompson, P. M., Holmes, C. J., Batth, R., Jernigan, T. L., \& Toga, A. W. (1999a). Localising age-related changes in brain structure between childhood and adolescence using statistical parametric mapping. NeuroImage, 9, 587-597.

Sowell, E. R., Thompson, P. M., Holmes, C. J., Jernigan, T. L., \& Toga, A. W. (1999b). In vivo evidence for post-adolescent brain maturation in frontal and striatal regions. Nature Neuroscience, 2, 859-861.

Sowell, E. R., Delis, D., Stiles, J., \& Jernigan, T. L. (2001). Improved memory functioning and frontal lobe maturation between childhood and adolescence: A structural MRI study. Journal of the International Neuropsychological Society, 7, 312-322.

Steel, J. G., Gorman, R., \& Flexman, J. E. (1984). Case Report. Neuropsychiatric testing in an autistic mathematical idio-savant: Evidence for nonverbal abstract ability. Journal of the American Academy of Child Psychiatry, 23, 704-707.

Stroop, J. R. (1935). Studies of interference in serial verbal reactions. Journal of Experimental Psychology, 18, 643-662.

Stuss, D. T., \& Knight, R. T. (2002). Principles of frontal lobe function. Oxford: Oxford University Press.

Stuss, D. T., Levine, B., Alexander, M. P., Hong, J., Palumbo, C., Hamer, L., Murphy, K. J., \& Izukawa, D. (2000). Wisconsin Card Sorting Test performance in patients with focal frontal and posterior brain damage: Effects of lesion location and test structure on separable cognitive processes. Neuropsychologia, 38, 388402.

Sylvester, C.-Y. C., Wager, T. D., Lacey, S. C., Hernandez, L., Nichols, T. E., Smith, E. E., \& Jonides, J. (2003). Switching attention and resolving interferences: fMRI measures of executive functions. Neuropsychologia, 41, 357-370. 
Goldsmiths Research Online

Szatmari, P., Tu., L., Allen, M., Finlayson, J., \& Bartolucci, G. (1990). Asperger syndrome and autism: Neurocognitive aspects. Journal of the American Academy of Child and Adolescent Psychiatry, 29, $130-136$.

Turner, M. (1997). Towards an executive dysfunction account of repetitive behaviour in autism. In J. Russell (Ed.), Autism as an executive disorder (pp. 57-100). Oxford: Oxford University Press.

Turner, M. (1999). Generating novel ideas: Fluency performance in high-functioning and learning disabled individuals with autism. Journal of Child Psychology and Psychiatry, 40, 189-201.

Varley, R., Siegal, M., \& Want, S. C. (2001). Severe impairment in grammar does not preclude theory of mind. Neurocase, 7, 489-493.

Waterhouse, L., \& Fein, F. (1982). Language skills in developmentally disabled children. Brain and Language, 15, 307-333.

Wechsler, D. (1974). Wechsler Intelligence Scale for Children Revised. New York: Psychological Corporation.

Wilson, B., Alderman, N., Burgess, P. W., Emslie, H., \& Evans, J. J. (1996). Behavioural Assessment of Dysexecutive Syndrome. Thames Valley Test Company.

Zelazo, P. D., \& Frye, D. (1997). Cognitive complexity and control: A theory of the development of deliberate reasoning and intentional action. In M. Stamenov (Ed.), Language structure, discourse and the access to consciousness (pp. 113-153). Philadelphia: John Benjamins.

Zelazo, P. D., Frye, D., \& Rapus, T. (1996). An age-related dissociation between knowing rules and using them. Cognitive Development, 11, 37-63.

Zelazo, P. D., Reznick, J. S., \& Pinon, D. E. (1995). Response control and the execution of verbal rules. Developmental Psychology, 31, 508-517.

Zilbovicius, M., Garreau, B., Samson, Y., Remy, P., Barthelemy, C., Syrota, A., \& Lelord, G. (1995). Delayed maturation of the frontal cortex in childhood autism. American Journal of Psychiatry, 15(2), 248-252. 
Goldsmiths Research Online

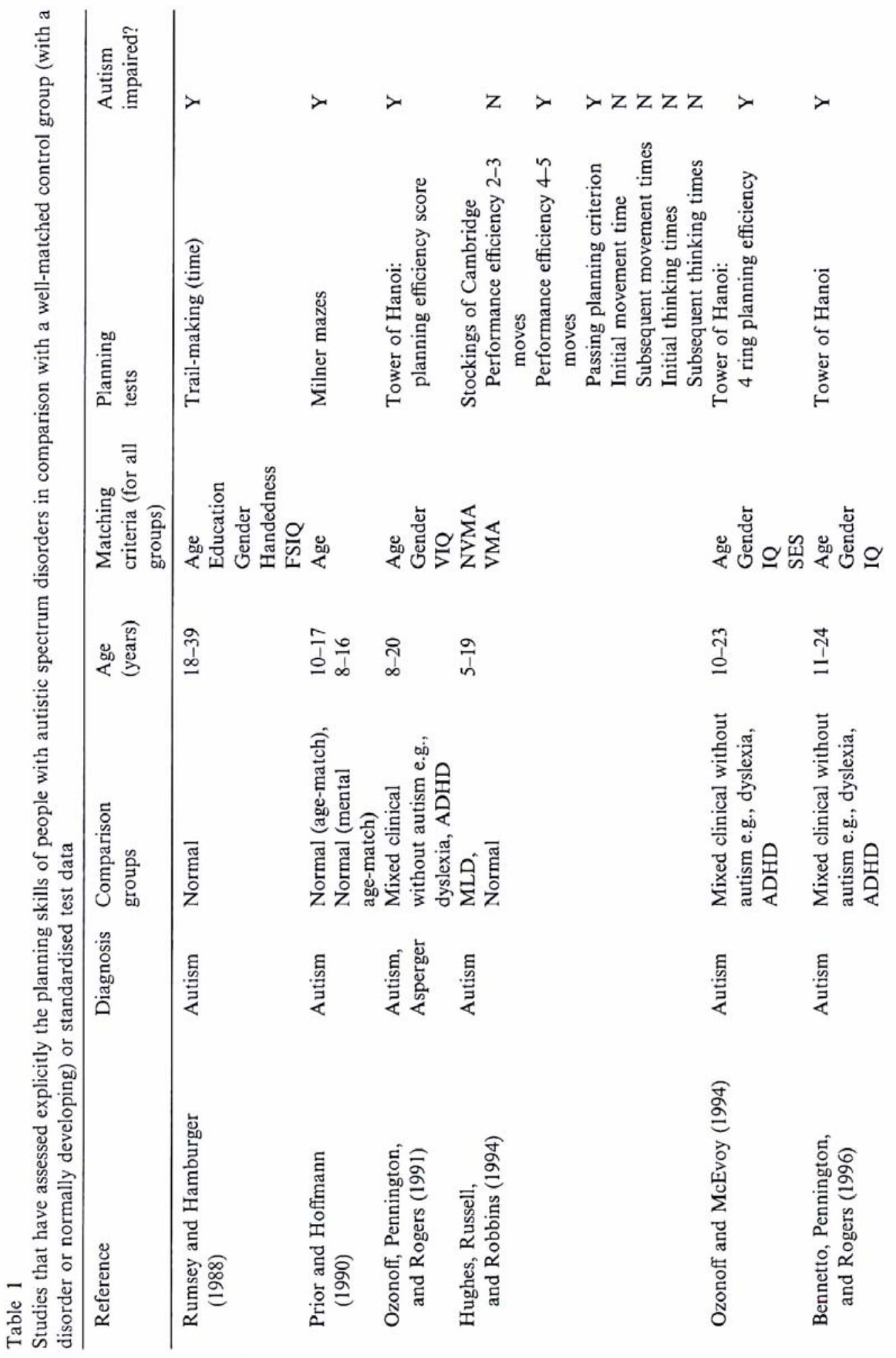


Goldsmiths Research Online

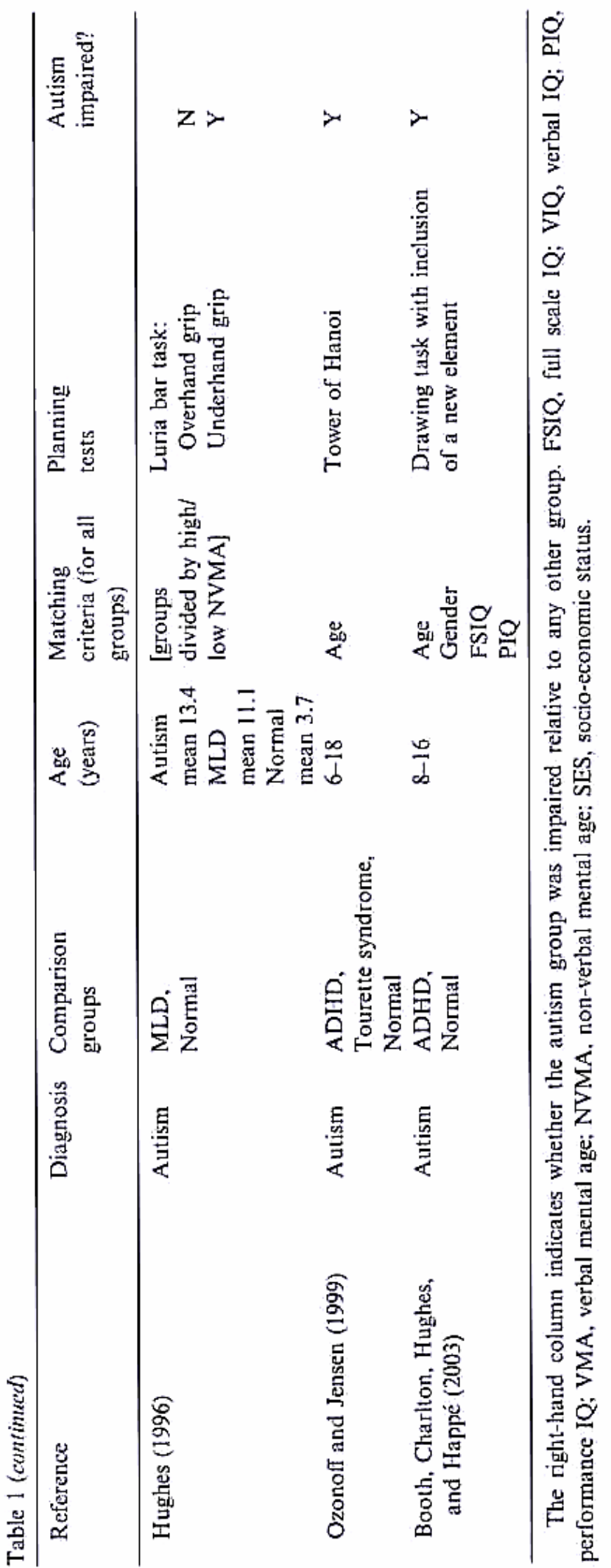


Goldsmiths Research Online

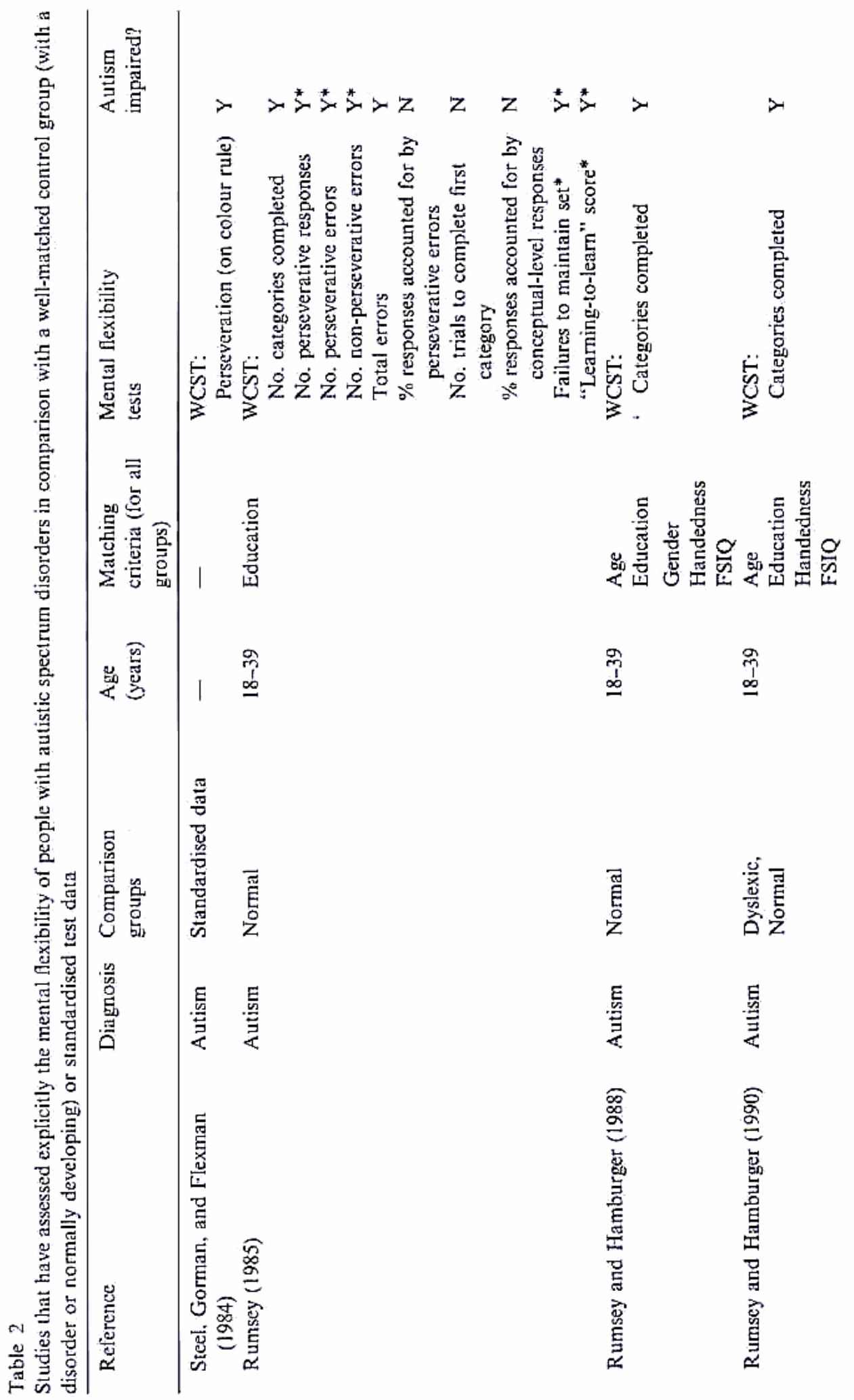


Goldsmiths Research Online

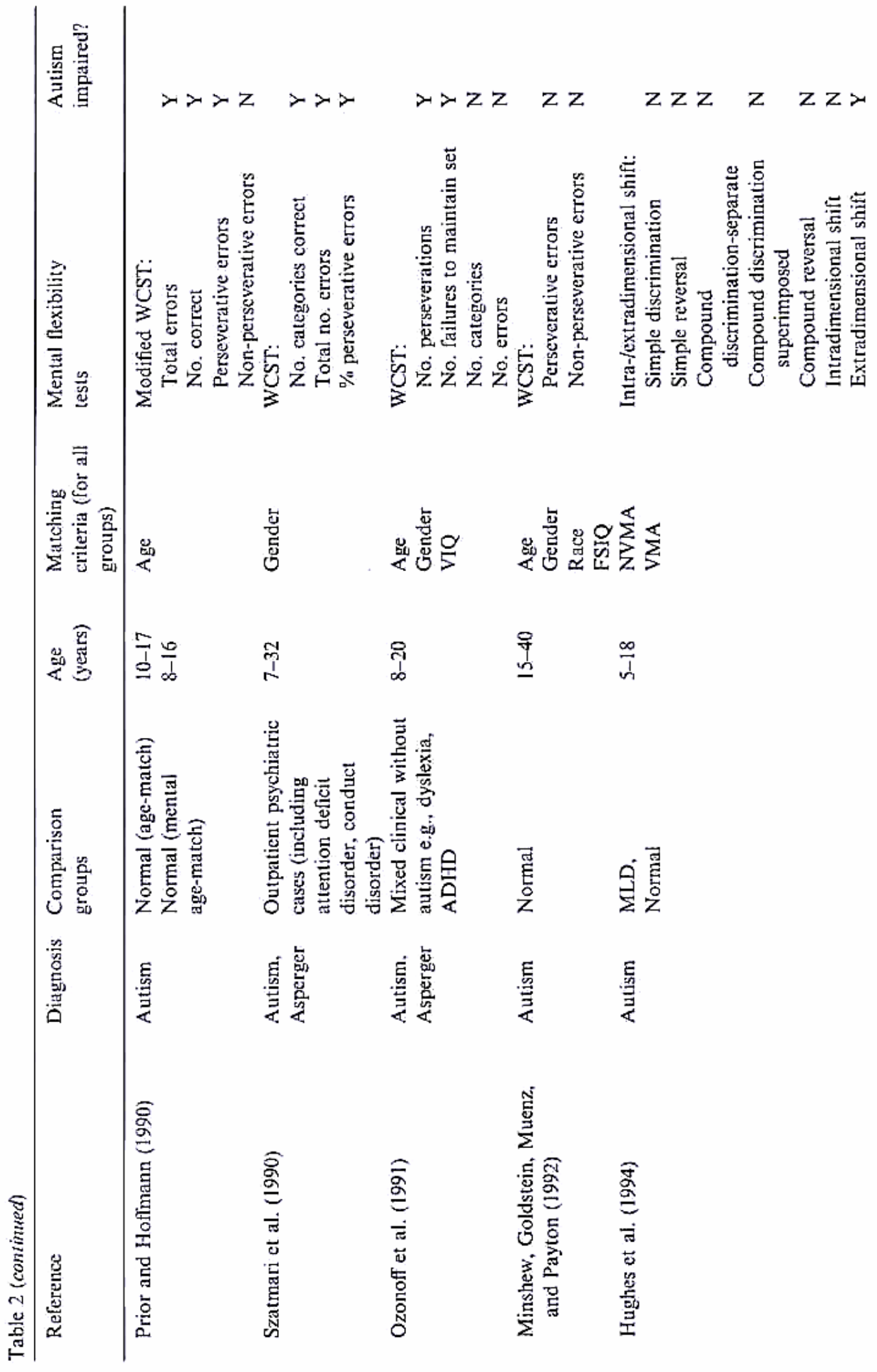


Goldsmiths Research Online

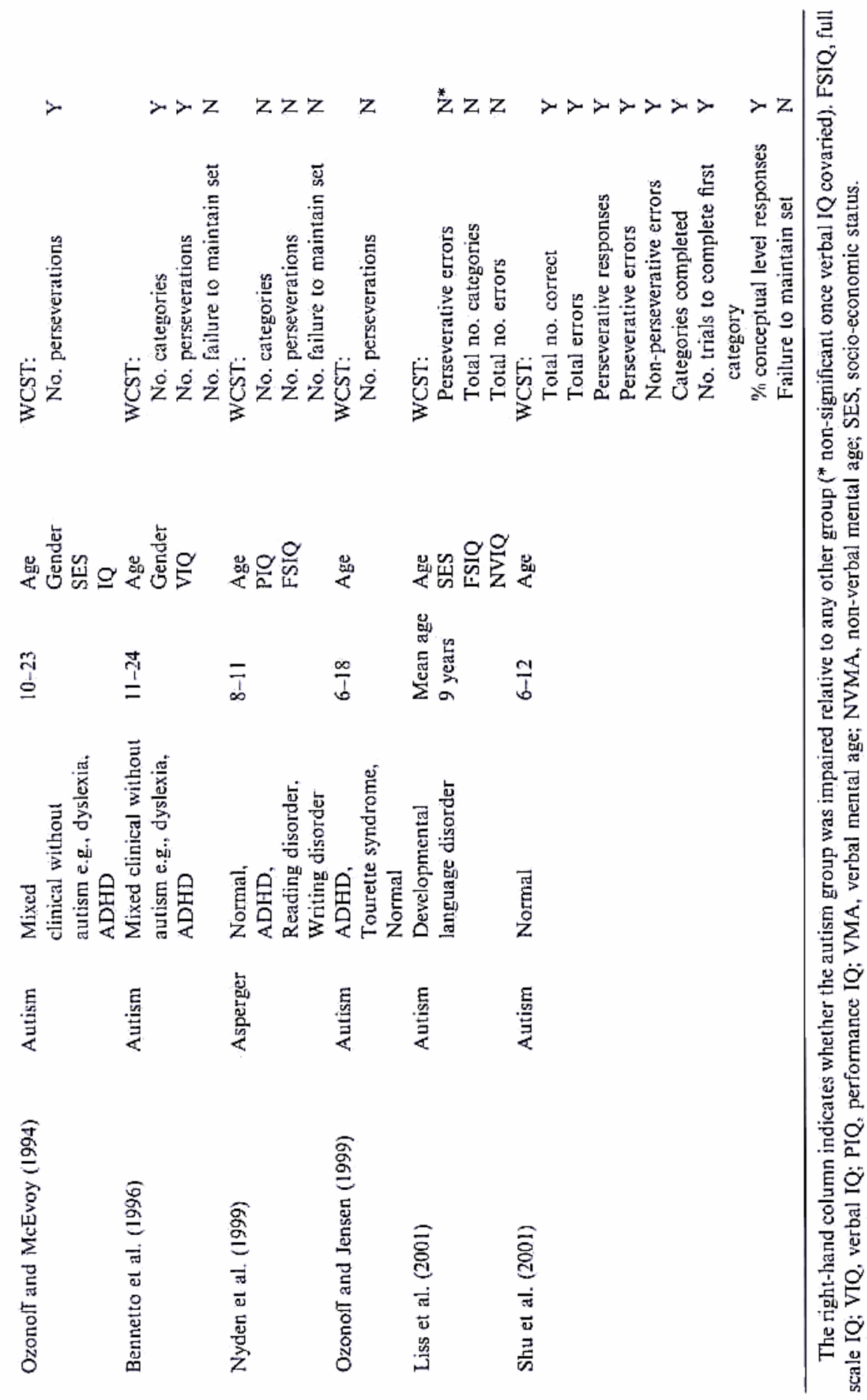


Goldsmiths Research Online

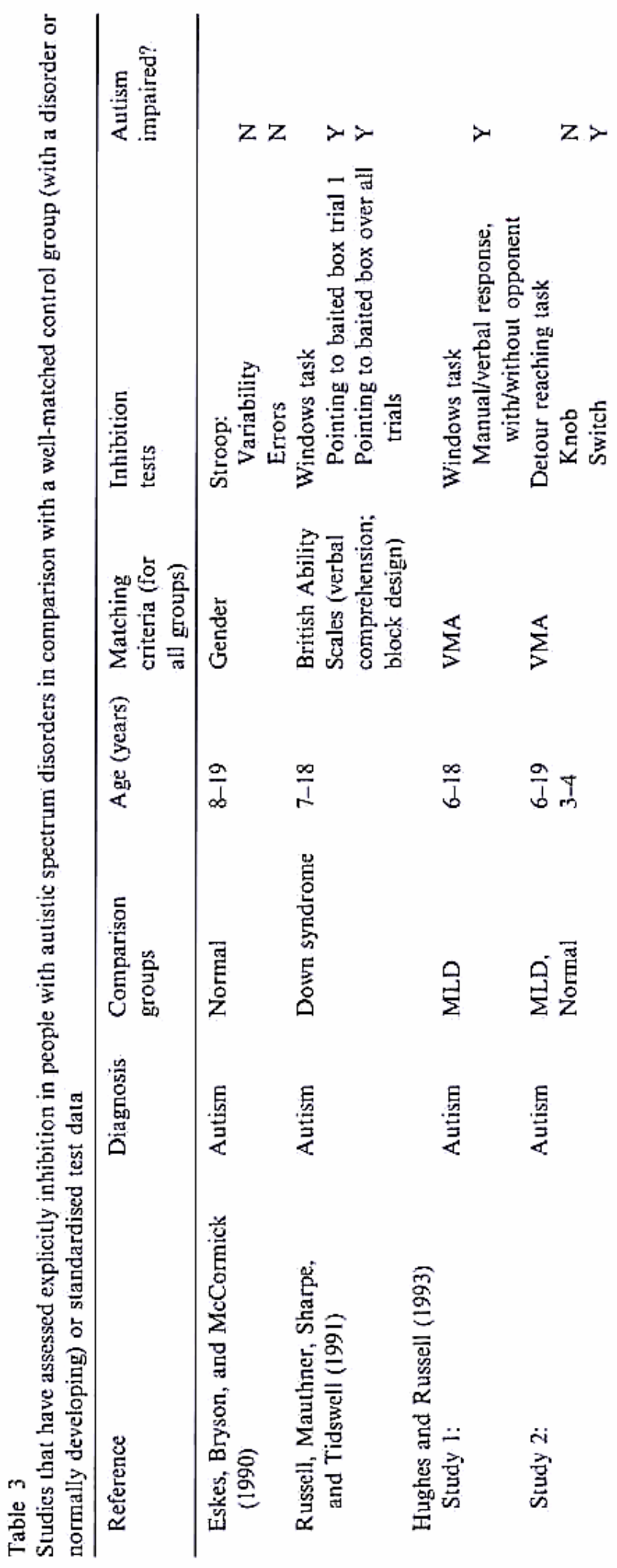


Goldsmiths Research Online

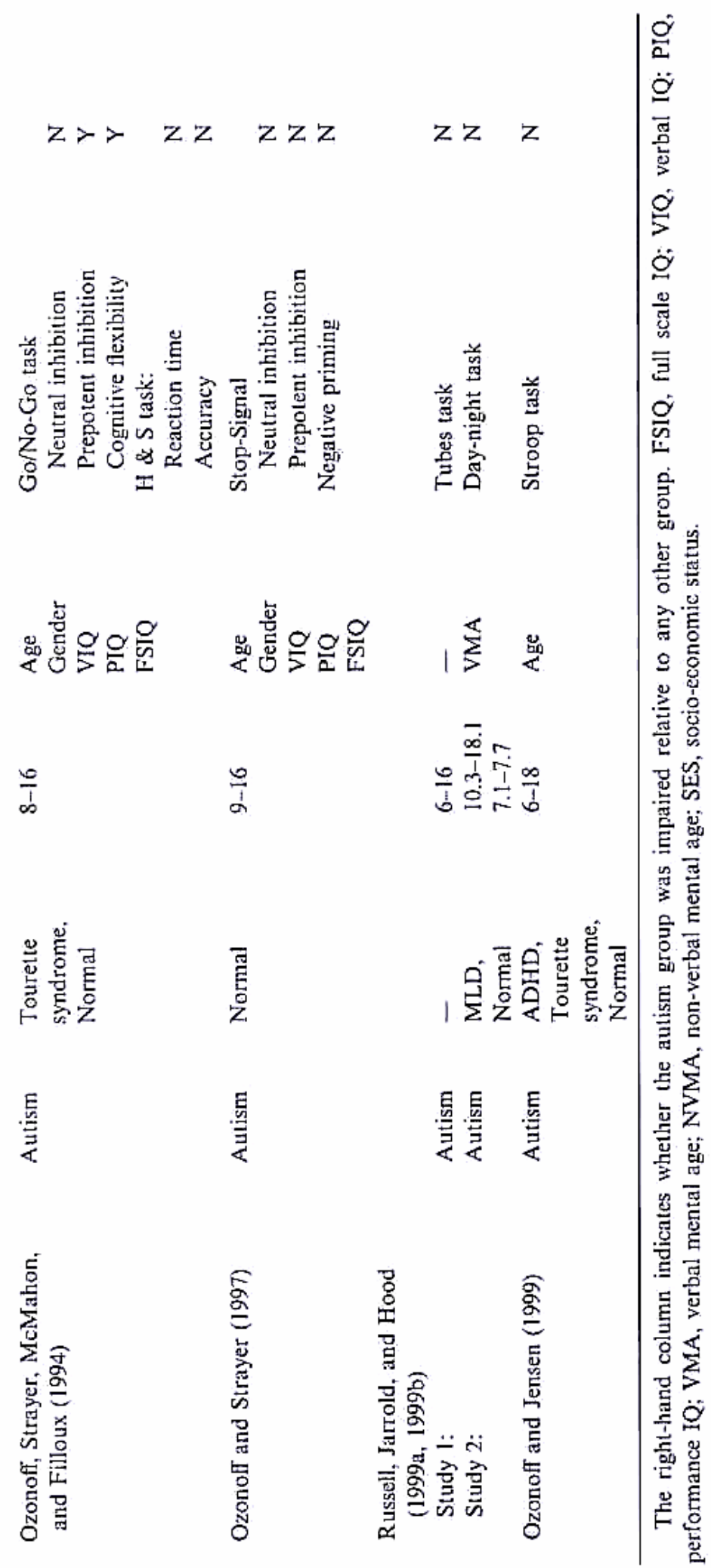


Goldsmiths Research Online

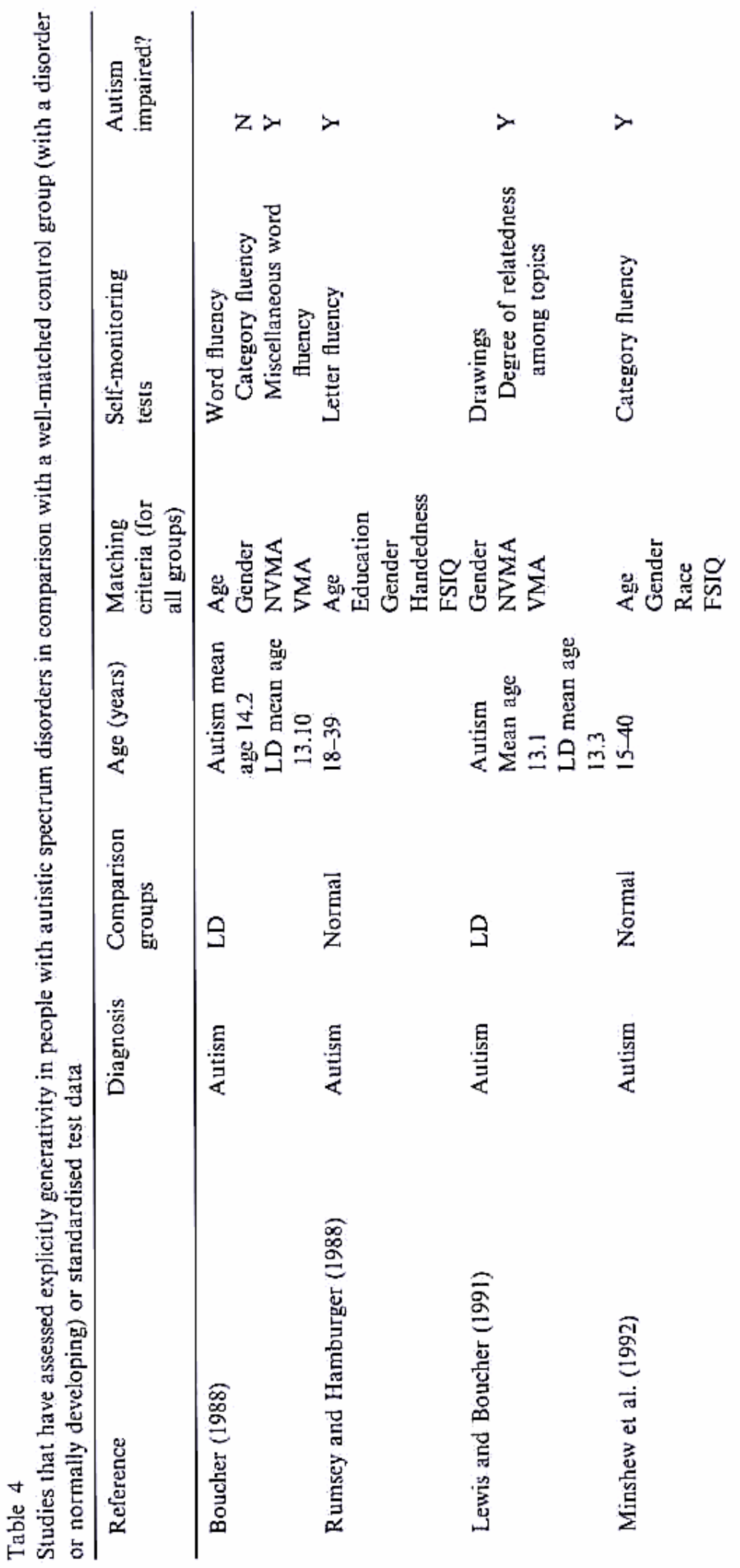


Goldsmiths Research Online

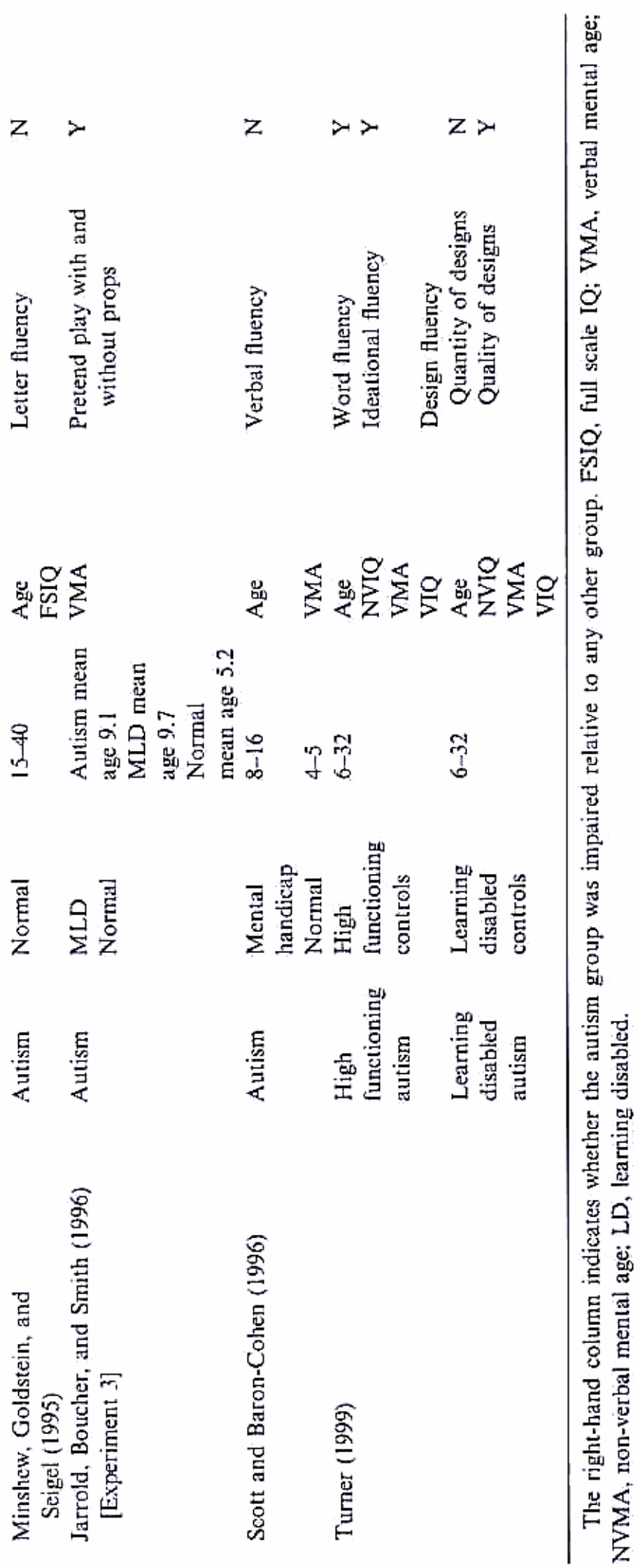


Goldsmiths Research Online

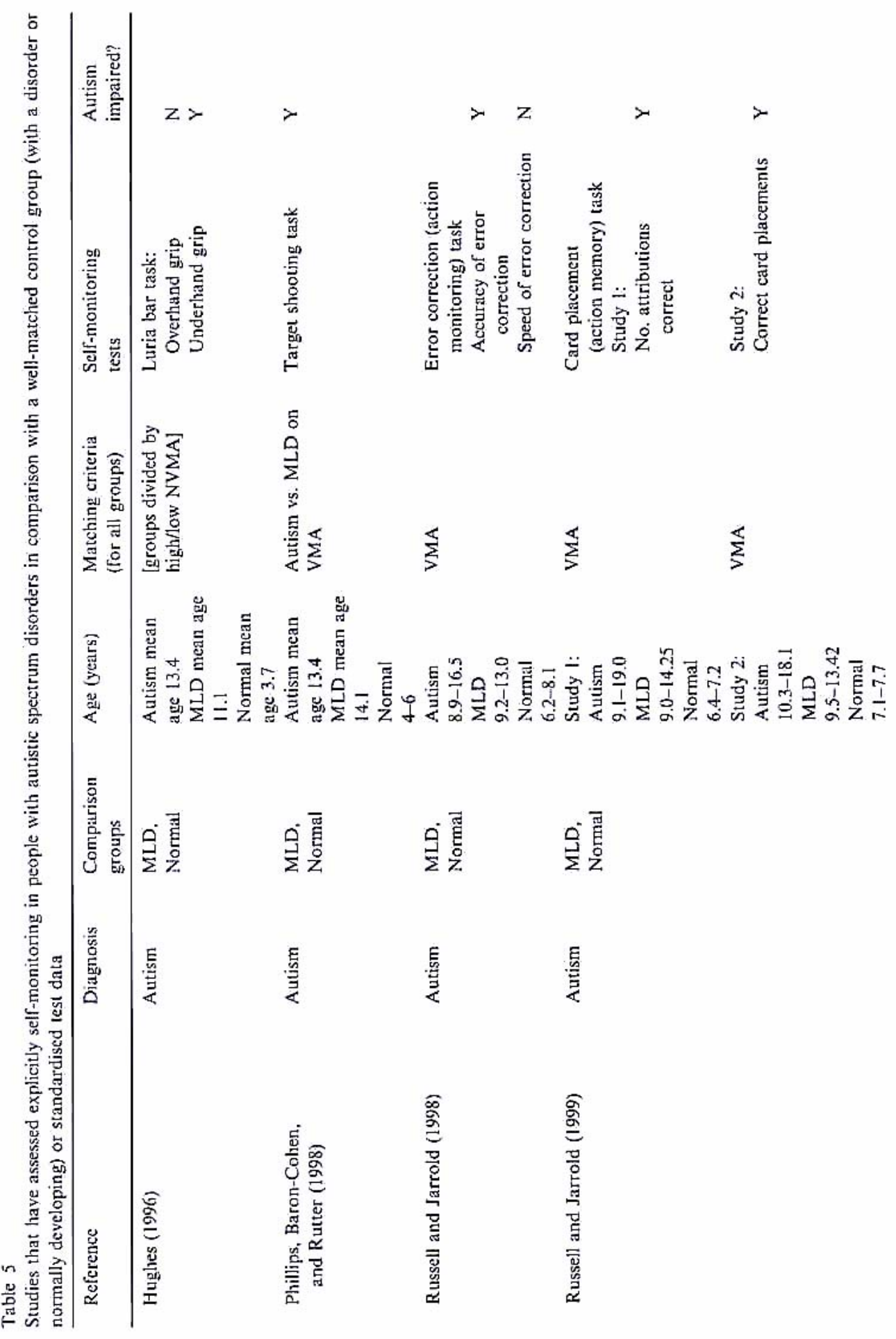


Goldsmiths Research Online

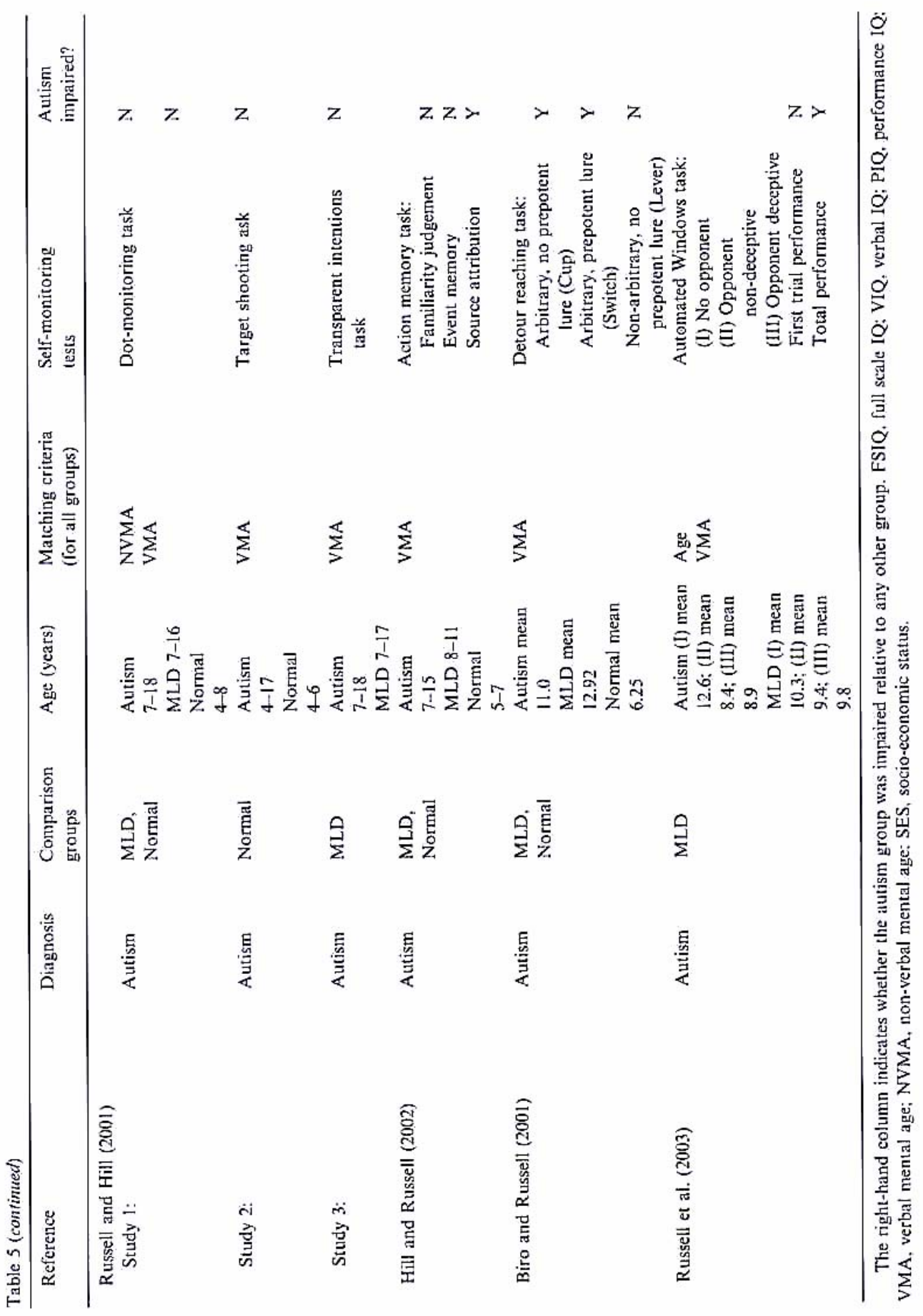

